•综述・

\title{
家马的驯化起源与遗传演化特征
}

\author{
陶克涛韩海格 赵若阳 图格琴芒来 ${ }^{*}$ 白东义 ${ }^{*}$ \\ (内蒙古农业大学动物科学学院内蒙古自治区马属动物遗传育种与繁殖重点实验室, 呼和浩特 010018)
}

\begin{abstract}
摘要: 人类文明发展历史中, 家马(Equus ferus caballus)曾是推动文化交流、促进人类社会发展的主要动力。关于 家马何时、何地被驯化以及在此过程中其遗传演化如何被人类影响等一直备受关注。近年来随着遗传学技术的发 展, 人们对该问题有了更为深入的理解。本文回顾了近二十年来相关研究所取得的成果, 探讨了家马的驯化起源 中心和驯化过程中的遗传演化特征, 并对未来的研究方向以及遗传资源保护提出了建议。分子标记遗传学和考古 学研究认为家马可能来自多个驯化起源地种群, 然而最近的古DNA研究结果表明, 现代家马的驯化起源可能比之 前人们所猜测的更加复杂, 古代博泰马被认为是最早被驯化的家马, 然而最近被证实并不是现代家马的直系祖 先。如此复杂的驯化问题可能从多学科的层次才能解析清楚。人类社会活动直接或间接影响了家马的演化历程, 特 别是工业革命以来家马的遗传基础发生了巨大变化, 其遗传多样性开始急剧衰退, 不少地方品种正逐渐走向衰落 甚至灭绝。为确保农业生态安全不受威胁, 建议加强家马遗传资源保护与动物遗传学和文化地理之间的联系研究。 关键词: 家马; 驯化起源; 遗传演化; 人工选育; 遗传资源保护
\end{abstract}

\section{The origins and genetic characteristics of domestic horses}

\author{
Togtokh Mongke, Haige Han, Ruoyang Zhao, Tugeqin Bao, Manglai Dugarjaviin*, Dongyi Bai* \\ Inner Mongolia Key Laboratory of Equus Genetics, Breeding and Reproduction, College of Animal Science, Inner \\ Mongolia Agricultural University, Hohhot 010018
}

\begin{abstract}
Throughout human history, the horse (Equus ferus caballus) was often involved in cultural exchanges and the development of various human societies. Human activities has directly and indirectly impacted the evolution of domestic horses, especially since the industrial revolution. There has been extensive research into when horses were originally domesticated and how humans impacted horse's genetic evolution during domestication. Recent developments in genomic technology has advanced our understand of horse genetic evolution. This review summarizes the results of the last 20 years of research on the domestication origins and genetic evolution of domestic horses, as well what is currently known about domestication centers and evolution characteristics of domestication. We also suggest avenues for future research directions and genetic conservation strategies. Molecular markers from genetic and archaeological research suggest that domestic horses may have originated from multiple populations. However, ancient DNA studies indicate a more complicated genetic history than previously thought, as the believed Botai ancestor to all domesticated horses has been disproven as the direct ancestor of modern domestic horses. To address these types of complex scenarios may need a multi-disciplinary framework to understanding the horse domestication. Human activities have shaped the evolution of modern domestic, driving both demographic collapse and low genetic diversity, especially, since the industrial revolution. A number of indigenous horse breeds are gradually declining and are becoming extinct. Therefore, in order to ensure that agricultural safety, we suggest strengthening the researches on the relationship between protection of equine genetic resources, animal genetics and cultural geography.
\end{abstract}

Key words: domestic horses; domestic origins; genetic evolution; artificial selection; genetic resources conservation 
家马(Equus ferus caballus)的成功驯化对人类 社会的运输、通信、战争及文化等产生了深远影响, 并且在塑造人类历史方面曾起到了决定性的作用, 从而象征了胜利、主权、财富、贵族和死亡等。数 千年来, 家马一直是推动人类社会发展的发动机。 家马帮助人类建设了城镇, 耕种了土地, 开拓了疆 域, 曾是人类的主要运输方式, 对人类经济和社会 发展的贡献无可争议。从时间的尺度来看人类已有 超过6,000年的用马历史, 虽然工业革命以来人类 社会经历了从农牧业生活到城市化工业化的惊人 转变, 但内燃机逐步取代家马的历史也不过只有百 年左右。今天家马在科学、艺术和军事中仍具有象 征性意义。家马还是研究解剖学、系谱学和运动科 学等学科的关键模型生物。表示内燃机功率的马力 (horsepower, hp) 的概念也是由詹姆斯·瓦特(James Watt)在18世纪以克莱兹戴尔重挽马为标准所提出 并且沿用至今(Holgate, 2018)。家马的发展历史其实 就是人类文明发展历史本身(Chamberlain，2006), 要了解人类的过去, 就需要了解家马的驯化历史。 因此, 家马驯化起源与遗传演化一直是学术界研究 的主题, 许多地区(东欧、西欧和欧亚草原等)被视为 家马驯化起源中心(Bendrey, 2010)。

人类活动对家马和野马的演化具有重要影响。
工业革命以来由于育种策略的改变, 人类对家马施 加的选择压力逐步增强, 品种间产生了不同的遗传 结构和分化特征, 从而培育出了表型各异的品种 (Kalbfleisch et al, 2018) (图1)。目前全球家马总数量 已达5,800万匹(FAO, 2015), 先后约 905 个品种被培 育出来(Librado et al, 2016)。然而人类活动使野马种 群遭遇灭绝或濒临灭绝。1909年, 最后一匹欧洲野 马(Equus ferus ferus)死亡, 该物种宣告灭绝 (Sandoval-Castellanos et al, 2017)。普氏野马(Equus ferus przewalskii)种群也一度仅剩下人工饲养的16 匹，1960年国际自然保护联盟宣布该物种的野外种 群已灭绝(Sarkissian et al, 2015)。庆幸的是普氏野马 经过欧洲研究机构半个多世纪的迁地保育, 成功维 持了一定数量的人工饲养种群并进行了繁殖, 目前 数量已恢复到约 2,109 匹, 但仍处于濒危状态 (Sarkissian et al, 2015)。家马地方品种面对商业引种 时处于同样的命运, 当与外来种质杂交, 由于遗传 湮没(genetic swamping)效应, 地方品种特有的基因 型会消失, 品种边界变得模糊, 品种鉴别特征不明 显。根据联合国粮农组织统计, 目前已有超过88个 地方品种灭绝(FAO, 2015)。此外, 由于育种者希望 标准化和改善家马品种的某些特性, 因此在培育过 程中常采用纯系育种策略和血统系谱登记制度, 因

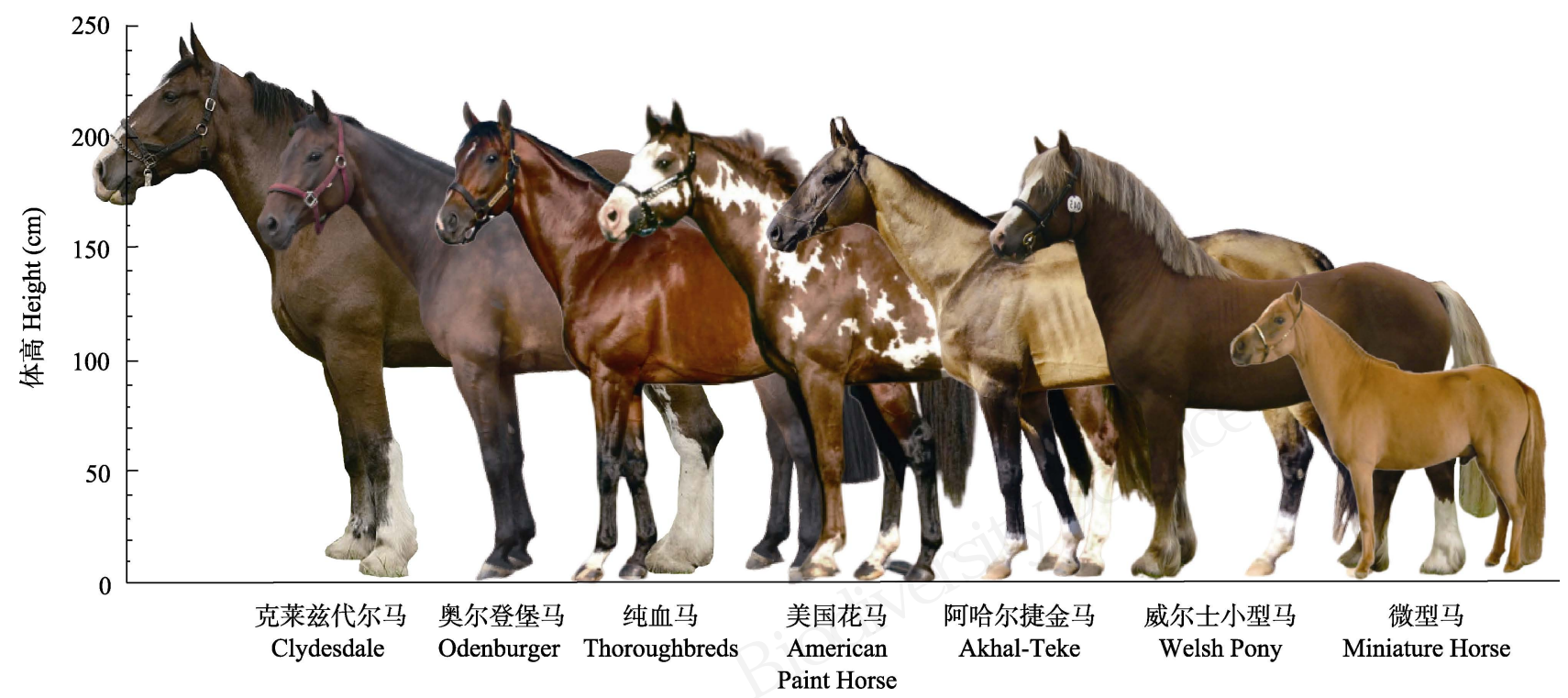

图1 家马不同品种体高对比示意图(以上图片均引自https://en.wikipedia.org/wiki。符合CC BY 2.0、CC BY2.5和CC BY-SA 3.0开放版权协议或属于公共领域)

Fig. 1 Comparison of body sizes of domestic horses of different breeds. Images sourced from https://en.wikipedia.org/wiki licensed under CC BY 2.0, CC BY 2.5 and CC BY-SA 3.0. 
而导致家马培育品种遗传多样性衰退。

生物学家对家畜驯化起源与演化研究至少可 以追溯到查尔斯・达尔文, 他用家畜的表型变异作 为《物种起源》和《驯化下的变异》等著作中有关 选择压力与起源演化关系的例子(Darwin, 1859, 1868)。家马的驯化起源和演化主要研究野生祖先、 驯化起源地、不同种群的分布与形成以及种群遗传 结构随时间和空间的变化等内容，涉及到包括遗传 学、考古学等在内的多学科及研究方法(Hunter, 2018)。通过观察不同时间和空间马的遗传变异有助 于更好地了解家马的驯化和遗传演化规律，对于家 马驯化起源研究与遗传资源管理具有启示意义。近 年来，随着DNA提取和测序技术的发展，该研究领 域已取得了长足进步。本文我们将回顾家马驯化起 源与遗传演化的研究进展, 梳理有关家马驯化中心 研究中取得的成果, 并综合分析人类社会活动对现 代家马遗传基础的形成所产生的影响, 最后对未来 的研究方向以及遗传资源的保护提出建议。

\section{1 家马驯化起源中心}

家畜的驯化是复杂的过程，有证据表明现代驯 化物种的形成可能源于几个驯化事件，或多个野生
种群(Groves \& Grubb, 2011)。现存野马(Equus ferus) 仅存家马和普氏野马两个亚种(Der Sarkissian et al, 2015), 其余野生近缘物种或亚种已灭绝。所以无法 通过野生种群的地理分布格局以及与家马的遗传 关系来推测家马野生祖先及其驯化起源地。遗传学 研究认为, 由于现代家马母系遗传多样性非常丰富, 有些单倍型具有高频率的地理分布特征。因此，现 代家马的形成可能来自于多个驯化起源地种群或 野马种群(Vila et al, 2001; Hill et al, 2002; Royo et al, 2005; Luis et al, 2006)。

1.1 “伊比利亚半岛驯化起源论”与野生近缘种基 因渗入

伊比利亚半岛(图2)是第二个全新世野马的主 要栖息地(Warmuth et al, 2011), 并与人类有着密切 的关系。在该地区发现了大量马化石和石器时代的 野马岩画，而岩画中的野马毛色表型与现代家马非 常相似(Lopes et al, 2005; Pruvost et al, 2011), 因此, 推测伊比利亚半岛可能发生过家马独立驯化事件。 线粒体DNA单倍型D1在现代伊比利亚家马品种中 具有高频率的分布(Jansen et al, 2002; Lopes et al, 2005; Royo et al, 2005; Lira et al, 2010), 而晚更新世 至全新世，野马在欧亚草原和伊比利亚半岛已产

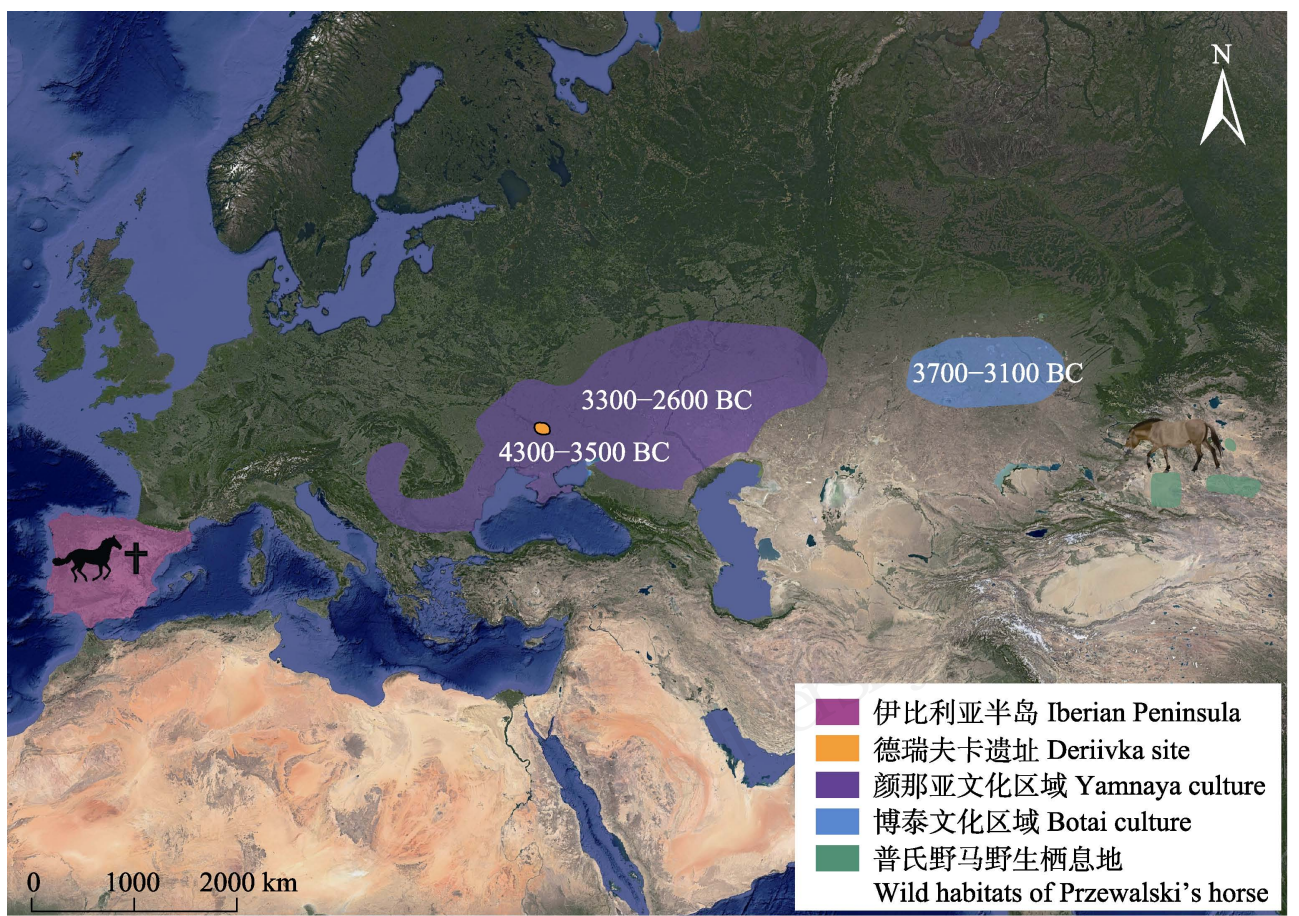

图2 家马驯化起源地研究相关区域和普氏野马野生栖息地分布示意图

Fig. 2 Distribution diagram of the related hypothetical centers of horse domestication and the nature habitas of Przewalski’s horse 
生了一定程度的分化(Cieslak et al, 2010)。因此该单 倍型被视为伊比利亚半岛可能发生家马驯化事件 的分子遗传学证据。然而, 古线粒体DNA研究表明, 单倍型D1在伊比利亚新石器时代和青铜时代的马 样品中并未得到证实, 而是存在于中世纪样品中。 因此，单倍型D1可能是青铜时代之后外来引入到 该半岛, 并不能代表分化的本土单倍型(Lira et al, 2010)。家马核染色体微卫星研究同样支持伊比利亚 半岛驯化假说: 研究发现伊比利亚半岛和里海地区 品种的遗传多样性显著高于中欧和北欧(Warmuth et al, 2011)。最近的一项基于全线粒体基因组的研 究表明, 家马在驯化过程中纳入了约73\%的野马线 粒体DNA多样性(Lippold et al, 2011b), 这意味着家 马在驯化过程中野生近缘种的基因渗入频繁。

古DNA的研究结果更倾向于野生种群的基因 渗入对家马遗传多样性的影响, 这也符合家马和野 马分享同一个生态位的情况。根据神经嵴细胞 (Neural crest cells)假说(Trut et al, 2009), 家马在驯 化过程中因人工选择产生了大量的毛色变异, 因此, Ludwig等(2009)以毛色基因型为线索探寻了家马的 驯化起源问题, 该研究发现 1.2 万年前欧洲和西伯 利亚马毛色主要以褐色或骝褐色为主。而在5,000 年前的伊比利亚马中只发现了 ASIP 基因的致黑基 因型变异, 然而此基因型在野马中同样存在。直到 中世纪, 伊比利亚半岛马中才出现了驯化导致的毛 色变异。由于伊比利亚半岛曾是冰期野马的重要避 难所(Hewitt, 2000), 并且该半岛本土野马种群在驯 化事件发生后仍幸存。因此, 野生近缘种的基因渗 入可能影响了现代伊比利亚半岛家马遗传多样性 的形成。Fages等(2019)的研究证明了这一点。该研 究通过对比 4,800-3,900年前的伊比利亚马和现代 家马的全基因组发现, 伊比利亚马对现代家马贡献 度只有 $1.4 \%-3.8 \%$, 并且这些古代伊比利亚马属于 已灭绝的野马种群。可见,由于基因渗入因素, 遗传 多样性程度并不能作为推断家马驯化起源地的有 力证据。

\section{2 “欧亚草原驯化起源论”}

从蒙古草原到哈萨克斯坦, 再到乌克兰草原, 构成了广衰的欧亚草原带。野马曾主要分布于该区 域(Sommer et al, 2011)。在过去的数千年间, 欧亚草 原被认为是印欧人迁移的十字路口(Allentoft et al, 2015), 而家马的驯化可能促进了印欧语系在欧亚
大陆的传播(Outram et al, 2009; de Barros Damgaard et al, 2018)。人类驯化家马的最初目的是对食物的 需求, 马肉和马奶含有高蛋白和低脂肪, 为欧亚草 原上的人类提供了充足的食物(Anthony, 2010; Wan, 2013)。随着乌克兰草原和哈萨克斯坦草原北部的新 石器时代遗址大量的马遗骸被发掘 (Anthony \& Brown, 2011), 欧亚草原已成为解开家马驯化起源 之谜的关键地区。

\subsection{1“德瑞夫卡驯化论”}

乌克兰-黑海草原的德瑞夫卡(Deriivka) (图2) 斯莱德涅斯多格文化(Sredny Stog Culture)遗址曾被 认为是家马驯化起源地之一, 该遗址可追溯至 4,300-3,500年前(Levine, 1990; Anthony et al, 1991; Mileto et al, 2017)。从20世纪60年代考古发掘以来, 这里出土了大量的马遗骸, 被认为是最早驯养家马 的地区(Levine, 1990; Anthony et al, 1991; Levine, 2005)。Anthony等(1991)对该遗址一匹具驯化特征 的公马前臼齿做了病理学 X射线扫描鉴定, 发现了 超过 $3 \mathrm{~mm}$ 深类似衔铁造成的磨痕(野马前其齿在自 然状态下只产生平均 $0.82 \mathrm{~mm}$ 深度的磨损), 认为这 可能是役用家马的最早最直接的证据。然而不同于 博泰文化遗址(Outram et al, 2009), 这匹公马前臼齿 的放射性碳定年分析表明其时间大概在公元前 800-200年间的斯基泰铁器时代(Anthony \& Brown, 2000), 晚于家马驯化的时间。此外, 关于该遗址 中马乳有机残留物的分析也并没有为家马驯化提 供新的见解(Mileto et al, 2017)。因此, 德瑞夫卡遗 址的早期马遗骸可能只反映了人类与野马的狩猎 关系。

\subsection{2 “博泰驯化论”与第二驯化起源中心}

哈萨克斯坦北部的博泰文化遗址(图2)为人类 养马史提供了最早的考古证据, 年代可追溯至 5,500年前(Gaunitz et al, 2018)。博泰文化是一种狩 猎文化, 即骑马猎马, 此遗址中出土的 30 万具动物 遗骸中 $99.9 \%$ 来自于马。另外还出土了马粪层、畜 栏基址、陶器等文物(Hanks, 2010; Anthony \& Brown, 2011; Bendrey, 2011; Librado et al, 2017)。役用可使 家马的某些骨骼形态发生变化, 所以可以通过度量 掌骨和臼齿的形态特征来区分家马和野马。该遗址 出土的5,500年前的马掌骨形态和臼齿磨损程度与 家马非常相似, 陶器内的有机残留物也被证实含马 乳和马肉成分, 这说明古代博泰人已经开始役用马 
和食用马肉马奶(Outram et al, 2009)。博泰遗址为家 马的驯化与利用提供了最早的考古学证据, 这似乎 暗示着现代家马可能起源于博泰文化繁荣时期的 博泰马。古基因组学研究表明, 博泰人是冰河时代 狩猎采集者的后裔, 由于野马种群数量逐渐减少, 博泰人对野马从狩猎转向了驯化。博泰人对马的驯 化可能与西伯利亚牧民驯化驯鹿的模式相似。驯鹿 同样可用于挤奶食肉以及骑乘，因此，西伯利亚牧 民从简单的狩猎完成了驯鹿的驯化 (de Barros Damgaard et al, 2018)。最近的研究显示, 博泰马并 非是家马的直系祖先, 而是普氏野马的直系祖先 (Gaunitz et al, 2018), 这意味着可能还存在第二个 驯化中心。另外, 青铜时代早期欧亚西部草原颜那 亚文化(Yamnaya Culture) (图2)的族裔在欧亚草原 发生了扩张(de Barros Damgaard et al, 2018), 这可 能迫使博泰人和他们的马向东迁移, 因为欧亚草原 东部(如蒙古国西部科布多盆地和中国新疆准噶尔 盆地东部一带) (图2)最终成了重返野外的普氏野马 的主要栖息地。另外, 博泰马占家马血统的比例极 低可能与 500 年前欧洲人将他们的家犬引入美洲最 终导致美洲原住民家犬品种灭绝的事件相似 (Larson et al, 2012), 因此博泰马可能同样是因为外 来家马的入侵导致了其血统的全面衰退。

综上所述, 当时除了博泰马系谱外, 可能另一 支独立的家马系谱在第二驯化起源地被成功驯化, 该驯化系谱可能还促进了其族裔在欧亚草原的迁 移和扩张, 并在此过程中纳入了少量博泰马血统。 目前第二个驯化中心是否与颜那亚等其他文化有 关还无法确定。

\section{家马的遗传演化}

\section{1 种群演化历史与种群结构}

DNA提取、扩增以及测序技术的发展极大地增 进了我们对马种群演化历史的理解。通过对比研究 古代和现代马基因组序列, 能够确定马不同种群之 间的演化关系, 基因交流假说可以解释种群间复杂 的相互关系。现有的遗传证据表明，马大约在 400-450万年前与斑马和驴完成了分化。在过去的 200 万年间, 马种群规模的波动主要与气候和栖息 地的变化有关。例如, 12.5 万年前的冰期和 $2.5-5$ 万 年前草原面积的减少, 均导致了马种群规模的大衰 减(Orlando et al, 2013)。普氏野马和家马是野马仅存
的两个亚种，分化于约3.8-7.2万年前，然而普氏野 马和家马祖先分化后仍发生了多次基因交流。现存 普氏野马个体基因组也有不同程度的家马遗传渗 入，这意味着并不是所有现存谱系都能代表普氏野 马基因库(Orlando et al, 2013; Schubert et al, 2014; Der Sarkissian et al, 2015)。

在过去的10年间，博泰文化遗址一直是探寻家 马驯化起源问题的核心, 然而最新的研究表明, 在 该遗址中出土的古代博泰马并不是现代家马的直 系祖先, 而是普氏野马的直系祖先, 这不仅意味着 现代家马的身世问题仍然是个谜团，同时也说明真 正意义上的野马种群已全部灭绝(Gaunitz et al, 2018)。现代家马种群经过数千年的驯化和选育已分 化出了种类繁多的品种。在此过程中，人类不同文 明的发展动态对家马品种的形成产生了重大影响。 公元7-9世纪，由于伊斯兰文明的扩张，欧洲、中亚 包括蒙古地区的家马遗传结构受波斯马的影响发 生了改变。在过去的约250年中，由于工业革命的冲 击和人工选育的加强, 现代家马遗传多样性骤降了 $16 \%$, 特别是欧洲纯系培育品种，其遗传多样性衰 退的同时也展现出了很强的种群结构和分化特征 (Fages et al, 2019)。最具代表性的例子是英国纯血 马, 虽然纯系育种和血统系谱登记制度保证了纯血 马优良的竞技性能(Thurtle, 2011), 并形成了非常强 的遗传结构, 但也不可避免地导致了其遗传多样性 的衰退。与此相反，亚洲地方品种由于人工选育的 力度较轻, 因此并未形成较强的种群结构, 并且遗 传多样性也较为丰富。最新的一项研究(Liu et al, 2019)表明，中国家马遗传多样性非常丰富，可以将 中国17个地方品种以地理分布分为西南、青藏高原 和北方平原 3 个地理类群。其中, 西南类群受青藏高 原和北方平原类群的遗传影响较大, 而普氏野马对 中国家马并没有显著的遗传影响。

\section{2 特殊性状的选育}

美国马理事会(AHC，2017)公布的最新数据显 示, 2017年美国马产业所产生的经济影响高达1,220 亿美元，比2005年增长了 $16 \%$, 并创造了170万个工 作岗位。这些数字表明了现代马产业对当今社会的 重要性。在多数家马品种中, 与竞技性能有关的性 状在育种计划中起着核心作用，这意味着人工选育 对现代马产业的发展具有重要影响。人类对家马运 动性状的选育已有千年的历史(Fages et al, 2019), 
但直到约300年前才选育出具有卓越运动性能的品 种。在家马全基因组关联分析 (genome-wide association study, GWAS)中, 运动性能通常被认为是“复杂 性状”, 多因素相互作用决定了骑乘或竞技比赛的 性能。然而有研究证明(Hill et al, 2010a), 马匹某些 运动性能也与单碱基变异有关。例如, 对于纯血马 的繁育重点一直集中在提高速度赛竞技性能上, 这 可能使其心脏、呼吸系统以及肌肉骨骼等功能受到 特殊选择压力。全基因组关联分析(GWAS)结果支 持了这一点, 发现肌肉生长抑制素基因(MSTN)的 基因型决定纯血马应对不同比赛距离的奔跑能力 (Binns et al, 2010; Hill et al, 2010a)。目前纯血马产业 已经实现了通过检测 “速度基因”为赛马的训练和职 业规划提供科学依据, 从而挖掘赛马最大潜能和减 少浪费。

走马快而平稳的步态对骑乘品质或轻驾车赛 马比赛同样非常重要。人类对走马的选育同样历史 悠久, 中国甘肃省出土的东汉青铜器铜奔马 (又称 马踏飞燕、马超龙雀等)所展现的即是典型的走马步 态(图3)。有学者认为该艺术品的塑造灵感可能源于 古代相马术(雷志华和高策, 2014), 可见古人对走马 的喜好。冰岛马是著名的走马选育品种, 关于该品 种步态能力的GWAS研究表明, DMRT3基因的单碱 基变异与走马步态能力有关(Andersson et al, 2012), 该基因型在其他走马品种中也得到了验证(Kristjansson et al, 2014; Promerová et al, 2014; Jäderkvist et al, 2015; Ricard, 2015)。中国走马代表性品种有产 于内蒙古的乌审马和甘肃省的岔口驿马, 而有关中
国走马步态能力的全基因组关联分析还有待研究, 这项工作可为中国地方马品种的鉴定和种质资源 的保护提供科学参考。由于篇幅有限, 这里仅举以 上两个突出的例子，更多的表型与基因的关联分析 示例见表1。另外, 有关家马毛色的选育研究, 赵若 阳等(2018)已作了详细的综述，这里不再赘述。

\section{3 驯化成本}

“驯化成本”学说认为, 在驯化野生物种的过程 会导致驯化物种基因组中固定或分离的有害变异 频率增加, 从而对品种选育产生不良的影响(Moyers et al, 2017)。人类在驯化家马的过程中不仅改 变了家马的运动、体型、性格等性状，同时也增加 了家马种群的有害变异频率，这极大地增加了家马 患严重遗传疾病的概率。例如，I型多糖咜积肌病 (polysaccharide storage myopathy type I, PSSM I) 是 一种遗传性肌肉疾病, 可引起肌肉疼痛、抽筋、细 胞损伤和进行性肌肉萎缩。该疾病是由骨骼肌糖原 合成酶(glycogen synthase 1, GYS1)基因的功能获得 性错义变异所引起。在挽马品种中患该疾病的比例 高达36\%, 在夸特马中也达 $10 \%$ (McCue et al, 2008)。古基因组研究显示, 家马的驯化选育过程一 直伴随着遗传负荷的增加。家马种群数量的衰减大 约从2,300年前开始，但在此期间家马的遗传负荷 基本保持稳定。直到从约250年前, 受工业革命和现 代育种的冲击, 家马种群数量出现大幅衰减, 遗传 多样性骤降了16\%并加剧了家马种群有害变异的累 积(Librado et al, 2017; Fages et al, 2019; Orlando \& Librado, 2019), 因此现代家马蛋白质编码区域已经

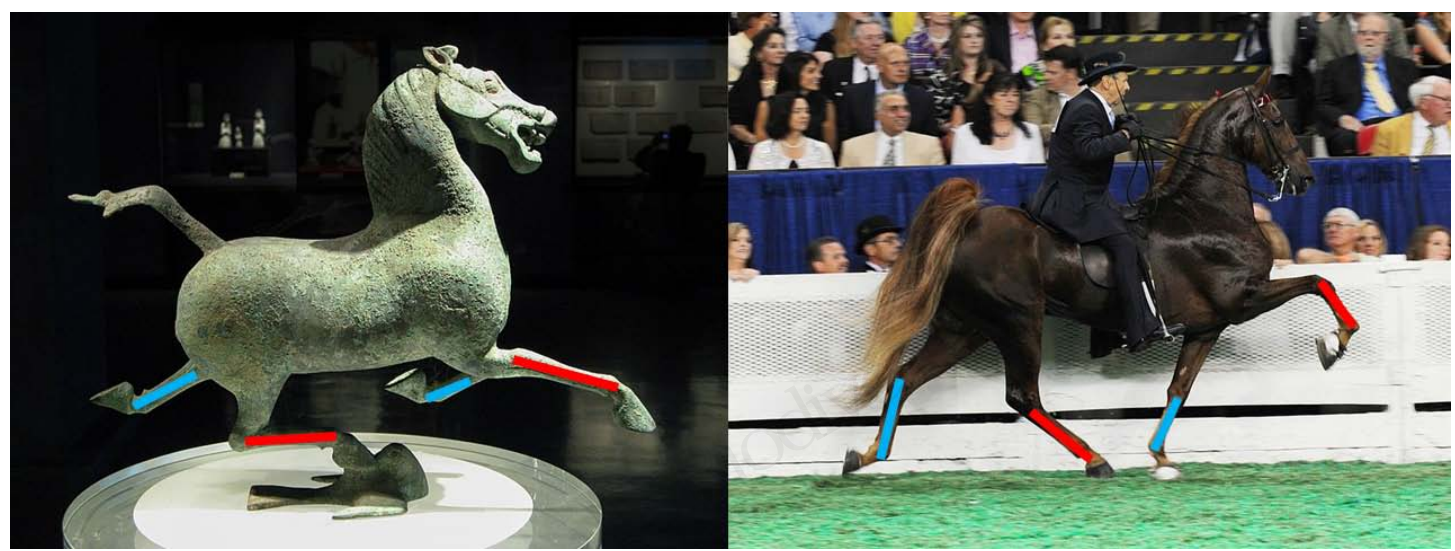

图3 铜奔马步态与走马步态对比图(以上图片均引自https://en.wikipedia.org/wiki, 符合CC BY 2.0、CC BY 2.5和CC BY-SA 3.0 开放版权协议或属于公共领域)

Fig. 3 Comprasion of the gait of Bronze Running Horse and ambling horse. Images sourced from https://en.wikipedia.org/wiki licensed under CC BY 2.0, CC BY 2.5 and CC BY-SA 3.0. 
表1 家马表型性状相关候选基因示例

Table 1 Examples for candidate genes with associations to the phenotypic traits of domestic horses

\begin{tabular}{|c|c|c|c|}
\hline 表型 Trait & $\begin{array}{l}\text { 基因或QTL区域 } \\
\text { Gene or QTL region }\end{array}$ & 代表性品种 Breed & 参考文献 Reference \\
\hline $\begin{array}{l}\text { 赛跑距离与冲刺能力 } \\
\text { Racing distance and } \\
\text { sprinting performance }\end{array}$ & MSTN & $\begin{array}{l}\text { 纯血马 Thoroughbreds } \\
\text { 夸特马 Quarter horse }\end{array}$ & $\begin{array}{l}\text { Binns et al, 2010; Hill et al, 2010a } \\
\text { Petersen et al, 2013b }\end{array}$ \\
\hline 赛跑能力 Racing performance & PDK4 & 纯血马 Thoroughbreds & Hill et al, 2010b \\
\hline $\begin{array}{l}\text { 步态类型(肢体协调能力) } \\
\text { Gait type (characterization of } \\
\text { motor coordination) }\end{array}$ & DMRT3 & $\begin{array}{l}\text { 冰岛马 Icelandic horse } \\
\text { 秘鲁帕索马、田纳西走马、 } \\
\text { 帕索菲诺、法国特罗特马 } \\
\text { Peruvian paso, Tennessee walking horse, } \\
\text { Paso Fino, French Trotter }\end{array}$ & $\begin{array}{l}\text { Andersson et al, 2012; Kristjansson } \\
\text { et al, 2014; Jäderkvist et al, } 2015 \\
\text { Petersen et al, 2013b; Promerová et } \\
\text { al, 2014; Ricard, } 2015\end{array}$ \\
\hline $\begin{array}{l}\text { 跳跃表演能力 } \\
\text { Jumping performance }\end{array}$ & $\begin{array}{l}\text { PAPSS2, MYL2, TRHR, } \\
\text { GABPA, NRAP, TBX4 }\end{array}$ & 汉诺威温血马 Hanoverian horse & Schröder et al, 2012 \\
\hline $\begin{array}{l}\text { I型多糖邑积性肌病(横纹肌溶解症) } \\
\text { Polysaccharide storage myopathy type } \\
\text { I, PSSM I (exertional rhabdomyolysis) }\end{array}$ & GYS1 & $\begin{array}{l}\text { 挽马品种 Draft horse breeds } \\
\text { 夸特马 Quarter horse }\end{array}$ & $\begin{array}{l}\text { McCue et al, } 2008 \\
\text { McCoy et al, } 2013\end{array}$ \\
\hline \multirow[t]{3}{*}{$\begin{array}{l}\text { 身体尺寸 } \\
\text { Body size }\end{array}$} & $\begin{array}{l}\text { LCORL, HMGA2, ZFAT, } \\
L A S P 1, N C A P G\end{array}$ & $\begin{array}{l}\text { 弗朗什-蒙塔涅斯马 Franches-Montagnes } \\
\text { 美洲矮种马 American miniature horse } \\
\text { 德保矮马 Debao pony }\end{array}$ & $\begin{array}{l}\text { s Signer-Hasler et al, } 2012 \\
\text { Makvandi-Nejad et al, } 2012 \\
\text { Kader et al, } 2015\end{array}$ \\
\hline & PROP1 & 弗里斯兰马 Friesian horse & Orr et al, 2010 \\
\hline & TВXЗ & 德保矮马 Debao pony & Kader et al, 2015 \\
\hline $\begin{array}{l}\text { 耳尖内翻 } \\
\text { Inward-turning ear tips }\end{array}$ & TSHZ1 & 马尔瓦里 Marwari horse & Jun et al, 2014 \\
\hline $\begin{array}{l}\text { 极寒环境适应性 } \\
\text { Extreme cold adaptation }\end{array}$ & $\begin{array}{l}\text { 顺势调控元件 } \\
\text { cis-regulatory }\end{array}$ & 雅库特马 Yakutian horse & Librado et al, 2015 \\
\hline $\begin{array}{l}\text { 高原低氧适应性 } \\
\text { High-altitude hypoxia adaptation }\end{array}$ & EPAS1 & 藏马 Tibetan horse & Liu et al, 2019 \\
\hline
\end{tabular}

出现了高比例的潜在有害变异特征(Schubert et al, 2014)。

\section{4 家马遗传多样性}

\subsection{1 家马父系和母系遗传多样性特征}

mtDNA序列多样性分析为现代家马的起源和 遗传多样性研究提供了有用的信息。现代家马在被 驯化过程中归化了大量的雌性野生近缘种群血统 (Warmuth et al, 2012; Der Sarkissian et al, 2015), 这 使得现代家马的线粒体遗传多样性非常丰富(Vila et al, 2001; Jansen et al, 2002; Lippold et al, 2011b; Achilli et al, 2012), 同时也使家马母系谱系的分类 复杂化。现代家马品种间以及与野生近缘种群共享 单倍型的情况很普遍(Warmuth et al, 2012), 其中至 少 73\% 的mtDNA谱系在家马驯化早期就已经存在 (Lippold et al, 2011b)。现代家马mtDNA多样性并不 完全随机分布, 有些单倍群与地理区域或品种高度 关联。例如, A2, C1, D1, F和 $\mathrm{H}$ 等单倍群具有高频率
的地理或品种分布特征: 单倍群A2与普氏野马, C1 与北欧矮马, $\mathrm{D} 1$ 与伊比利亚地区及西北非洲等品种 高度关联(Jansen et al, 2002), 单倍群F在东亚品种 中具有高频率的分布，单倍群 $\mathrm{H}$ 广泛分布于中国南 方家马种群(96.8\%) (Yang et al, 2017)。古线粒体 DNA研究(Librado et al, 2017)发现, 现代家马线粒 体多样性与青铜时代家马驯化早期阶段的斯基泰 马相似，说明青铜时代以来家马线粒体遗传多样性 得到了较好的延续。

相比家马线粒体DNA, 现代家马Y染色体遗传 多样性则极低。这与家马在驯化过程中的性别偏向 性育种策略有关(Lindgren et al, 2004; Wallner et al, 2013)。古代家马基因组数据显示，早期驯化的家马 $\mathrm{Y}$ 染色体遗传多样性与线粒体相似，同样具有很高 的遗传多样性。至少2,800年前, 斯基泰公马Y染色 体单倍型还非常丰富。因此, 在家马驯化初期, 种 公马奠基者种群还可以自由地参与繁殖。而在 2,000 
年前开始, 家马种公马的遗传多样性开始出现逐步 衰退的迹象(Lippold et al, 2011a; Librado et al, 2017; Fages et al, 2019), 到中世纪以后出现了大幅度衰退 的趋势。例如, 拜占庭马(公元287-861年)和蒙古帝 国的马(公元1206-1368年)多态性虽然比较低, 但高 于现代家马水平。而早于这两个时期的家马, 如拉 坦诺马、罗马马和高卢-罗马马则展现出了丰富的 多样性(Fages et al, 2019)。直到约250年前, 为了标 准化和改善家马品种的某些特性, 在纯系育种过程 中家马经历了大量的近交繁育, 从而导致了很多雄 性血统的消失(Orlando \& Librado, 2019)。现代家马 欧美主要品种的Y染色体单倍型极为贫乏, 其中一 个被命名为 “皇冠” 的单倍群占据了大多数欧美品种 血统。该单倍群主要来自于约700年前引进到欧洲 的阿拉伯马和土库曼马血统。最具代表性的欧洲品 种是英国纯血马, 该品种是著名的运动型品种, 在 比赛中以速度和冲刺能力而闻名, 该品种常被用于 引种杂交改良。土库曼马单倍型是英国纯血马的主 要单倍型, 因此, 该单倍型在其他欧美运动型品种 以及一些地方杂交品种中也广泛分布(Wallner et al, 2017; Felkel et al, 2018)。Felkel等(2019)通过双等位 基因标记构建了现代家马Y染色体精细单倍型网络, 也证实了西方家马父系单倍型的分化时间晚于家 马驯化的时间。

与欧美家马相比，亚洲家马受现代育种策略的 影响较晚。以现有的研究结果来看, 虽然一些地方 种群如三河马、阿巴嘎黑马和百岔铁蹄马等的父系 单倍型受到了英国纯血马的侵蚀, 但有些地方品种 如雅库特马、乌珠穆沁马和乌审马等种群仍保留着 较为丰富的Y染色体多样性(Librado et al, 2015; Han et al, 2019)。这表明, 亚洲地方马品种仍保留着古代 家马的单倍型, 而在欧美多数品种中这些单倍型可 能由于现代育种压力已丢失。

\subsection{2 家马不同种群常染色体遗传多样性特征}

简单序列重复(SSR, 也称为微卫星)和单核苷 酸多态性(SNPs)在群体遗传学中常被用于量化种群 之间的遗传差异。SSR和SNPs分子标记也常用于家 马的遗传多样性研究。本文总结了基于SSR和SNPs 分子遗传标记关于家马常染色体遗传多样性的研 究进展(附录1, 附录2), 通过比较不同品种遗传多 样性的差异程度, 我们认为种群数量、地理分布和 育种策略等对不同家马品种的遗传多样性具有明
显的影响:

(1)种群数量多、低选择压力、种内表型丰富、 开放育种的品种具有高遗传多样性。自由牧养的亚 洲地方品种多属于此类，由于育种者采取随机交配 的繁育管理策略，其遗传多样性往往显著高于其他 品种。具有代表性的品种包括蒙古马、哈萨克马、 图瓦马等(Tozaki et al, 2003; McCue et al, 2012; Chysyma et al, 2017)。值得一提的是, 在图瓦马中发 现了欧洲马品种未发现的等位基因HMS1R (Chysyma et al, 2017), 推测诸如图瓦马等地方品种可能 仍保留着原始驯化种群的等位基因库。另外，由于 共同起源祖先或基因交流等因素，地理分布较近的 品种间具有较近的亲缘关系。如中国地方马品种之 间，图瓦马与蒙古马和哈萨克马之间以及不丹地方 马品种之间亲缘关系较近(Ling et al, 2011; Chysyma et al, 2017; Dorji et al, 2018)。

(2)高选择压力、封闭育种、遭受遗传瓶颈效应 影响和种群数量少的品种具有低遗传多样性。由于 育种者希望标准化和改善家马品种的某些特性，因 此选育优良的纯合重组基因型非常重要。为了防止 种间的基因交流，在培育过程中常采用纯系育种策 略和血统系谱登记制度, 导致培育品种的遗传多样 性降低, 并且由于遗传漂变等因素最终促使其产生 较强的遗传分化, 如纯血马、美国阿拉伯马、克莱 斯戴尔马等(McCue et al, 2012; Petersen et al, 2013a)。濒危品种则由于遗传瓶颈效应而发生遗传 多样性衰退。例如, 伊比利亚半岛的索雷亚马种群, 由于保育自 12 匹基础繁育母群, 因此正在经历严重 的瓶颈时期，遗传多样性极度降低 (Luis et al, 2007)。日本 8 个地方品种的遗传多样性同样非常低, 也与其种群规模较小有关(Tozaki et al, 2019)。

(3)原产地种群遗传多样性高于其扩散地衍生 种群。分子群体遗传学的研究显示, 同一品种或同 一宗源品种在地理分布上存在遗传多样性差异。如 阿拉伯马原产自中东, 因此中东阿拉伯马种群的遗 传多样性要高于欧美种群, 这与欧美种群远离原产 地而导致的种群数量少有关, 并且由于遗传漂变和 瓶颈效应, 某些衍生种群产生了较高程度的分化, 如美国达文波特阿拉伯马种群(Khanshour et al, 2013)。另外, 日本地方马品种被认为衍生自蒙古马 种群, 蒙古马包含了其所有等位基因, 因此日本地 方马遗传多样性贫乏除了遗传瓶颈以外可能还与 
地理隔离有关(Tozaki et al, 2003, 2019)。

\section{家马种群衰退与遗传资源保护}

马遗传资源的衰退是由多种因素(如自然栖息 地遭到毁坏、过度捕猎、气候变化、外来种质的引 进及不加选择的杂交、生产方式的改变、由社会经 济因素引起的生产者的偏好等等(Rege \& Gibson, 2003)协同造成的结果。但可以肯定地说，目前大部 分马种群的消失事件都应归处于人类的经济活动。 保护马遗传资源仍需要社会理念的重大转变, 社会 各界必须充分认识到家马遗传资源的珍贵性，只有 充分利用马遗传资源才能最大限度地为多数农牧 民谋求最长远的利益。然而遗憾的是目前由于非可 持续的经济活动(如为了提高本地马某些经济性状 而与外来种质不加选择地杂交), 家马遗传资源正 在遭受不可逆转的破坏。

现代马业的长期健康发展依赖于传统农牧业 保留下来的地方马品种的遗传多样性。然而, 现代 农业的发展却正在迫使畜鿖遗传多样性迅速下降。 根据FAO畜禽多样性信息系统(DAD-IS)统计, 目前, 全球约 905 个家马品种中 156 个品种正处于极危状 态, 超过 70 个品种处于濒危状态, 而 88 个品种已经 灭绝(FAO, 2015; Librado et al, 2016)。保护生物学家 普遍认为任何生态系统或物种都不应消失或灭绝 (Primack, 2009)。现实却是大量的家马品种正濒临 灭绝而社会用于保护它们的资源却非常有限。因此, 建立完善的种质保护与发展利用计划来适应现代 马产业的发展趋势显得更加迫切。由于普氏野马和 一些地方马品种仍保持着一定的古代马的形态、行 为和健全的遗传多样性, 因此对那些具有独特遗传 结构、高度濒危以及具备经济、生态、历史文化以 及科学研究价值的马品种的保护应给予特别重视 (Oldenbroek, 1999)。近年来中国家马遗传资源流失 的现象日益严重, 除了因外来引种杂交引起遗传湮 没 (genetic swamping), 导致遗传资源衰退以外，不 少地方品种的数量也在下降。例如, 鄂伦春马、晋 江马、宁强马等 3 个地方马品种已处于濒危状态。 2014年, 国家畜禽遗传资源管理委员会公布了新的 《国家级畜禽遗传资源保护名录》(http://www.moa. gov.cn/nybgb/2016/shierqi/201711/t20171125_5919544. $\mathrm{htm}$ ), 并确认了国家级畜禽品种资源保护场(区)。目 前, 中国已有 7 个家马地方品种入选新的国家级畜
禽遗传资源保护名录, 分别为蒙古马、鄂伦春马、 德保矮马、晋江马、宁强马、岔口驿马、焉老马等, 这些措施有望对中国家马遗传资源的保护起积极 作用。

\section{4 总结与展望}

近年来随着分子遗传学技术的发展, 有关家马 驯化起源与遗传演化的研究取得了重要进展。除了 缩小了考古学和遗传学提出的驯化起源地范围外, 还初步探明了家马在驯化过程中的遗传演化历史。 另外，普氏野马也被证明并非真正意义上的野马 (Gaunitz et al, 2018)。这些研究无疑加深了人们对家 马驯化与演化的理解。与此同时，也凸显了多学科 证据在解释复杂和富有争议的家畜驯化过程中起 到的关键作用。

然而, 人们对家马驯化和演化过程的理解还远 远不够，对于现代家马的直系祖先仍有争议，还无 法确定现代家马驯化起源中心以及不同野生种群 的遗传渗入对现代家马形成的影响。随着人类社会 的发展，对家马的性能会产生不同的要求，所以家 马的驯化和育种是动态持续的过程。高度专业化选 育使得现代家马种间分化非常明显，但同时丢失了 大量遗传多样性。因此，现代家马的遗传结构很大 程度上已被改变, 简单地通过研究其遗传背景已很 难推测准确的驯化起源地。古基因组学技术的发展 对该领域的研究带来了新的契机，通过对比大量的 跨时间和空间的马样品基因组信息，可以绘制出家 马遗传演变的历史图景以及不同群体间的遗传关 系网络，这有助于解答家马驯化起源地及不同种群 的形成等科学问题。然而, 要完成如此复杂的研究 工作需要加强国际科研团体间的合作以打破样品 和技术的局限。中国自古以来是养马大国，就目前 国内研究现状而言，探讨家马驯化起源问题的遗传 学依据还多停留在现代家马遗传变异层面, 还有待 开展古基因组学领域的研究，将对揭示中国家马的 起源及形成之谜提供新的见解。此外，在全基因组 关联分析的基础上还可以通过表观遗传学、转录组 学、微生物基因组学等多组学结合的方法进一步解 释家马品种间的形态、行为以及适应性调节等生物 学表型特征的差异, 进而加深人们对家马驯化与演 化规律的理解。

经过半个多世纪的努力, 在马属濒危野生物种 
遗传资源保护方面已取得了丰富的经验，最为成功 的案例便是对普氏野马种群数量的恢复工作, 对于 极危物种的保护具有示范意义。普氏野马曾被认为 是地球上唯一幸存下来的“野马”物种，因此作为马 属动物旗舰种吸引了更多的社会关注度, 这对其保 护起到了积极的作用。如今超过 $1 / 4$ 的地方品种已灭 绝或濒危。目前, 中国为了极大限度地保留家马遗 传多样性, 在家马种质资源的保护策略中, 主要采 用由养畜人继续培育及育种的活体原产地保护为 主的方式进行, 而在保护工作中所面临的困境仍是 有限的资金和资源。因此，在现有的条件下如何防 止家马遗传多样性丧失变得尤为重要。以作者的浅 见, 至少有以下几方面在家马遗传资源保护工作中 值得关注:

(1)优先加强保护遗传多样性丰富和具有极端 环境适应性演化的古老地方品种, 从而为未来不同 育种生产需求提供遗传资源。遗传多样性对物种的 长期生存非常重要(Primack和马克平, 2009)。例如, 蒙古马具有丰富的遗传多样性, 这表明该品种是非 常古老的品种, 并且受人工选择影响较小。另外, 蒙古马对其他家马品种的形成也产生了重要影响, 俄罗斯的雅库特马与蒙古马的遗传关系非常近, 该 马种约在公元13-15世纪从蒙古地区迁移到雅库特 地区, 并非雅库特土著马种。目前, 雅库特马已经 产生了适应极寒环境的演化特征, 能够适应 $-70^{\circ} \mathrm{C}$ 的北极圈极端极寒环境(Librado et al, 2015), 这离 不开其丰富的遗传多样性。藏马被认为是古老的高 原家马品种, 以能够长期适应藏区极端的低氧环境 而闻名。最近的研究显示, 藏马对高海拔适应性与 EPAS1基因的表达有关(Liu et al, 2019)。

(2)细化地方品种的父系和母系保种方案。从上 文中可以看到家马地方品种母系和父系遗传多样 性受侵蚀的程度和趋势不同，可以根据不同种群所 面临的实际问题来实施更有针对性的保种措施。另 外, 应加强对种公马遗传资源的保护, 从而提高保 护效率。

(3)确定地方旗舰家马品种。如蒙古马和哈萨克 马等是著名的地方品种, 对世界其他家马品种的形 成具有重要影响, 同时它们也是草原文明的重要文 化符号并具有传统文化象征意义, 能够吸引公众关 注, 因此可以通过确立旗舰保护品种来呼吁人们对 地方马品种种质资源的重视。
(4)建立家马遗传资源综合保护发展体系。由于 现代马产业的核心是竞技体育运动，因此可以把家 马遗传资源保护、传统赛马业以及经济发展等诸多 方面结合起来形成综合保护发展体系，从而形成具 有区域特色的现代马产业。

(5)与当地居民建立家马遗传资源保护合作关 系。地方马品种是其原产地人类活动的结果, 数千 年来传统的定居者已经建立了对自然资源保护的 传统文化信仰体系，大多数当地人其实愿意与政府 一道支持当地遗传资源的保护，因此当地人是家马 遗传资源保护工作的潜在而重要的合作伙伴。现实 中那些支持自然资源保护的当地人在家马遗传资 源保护中起着重要作用。例如, 赤峰市克什克腾旗 百岔沟一带的百岔铁蹄马正面临灭绝的威胁, 为此 当地牧民在非常艰难的条件下成立了保种协会，并 正在做抢救性保种工作。另外，一些支持自然资源 保护的高校科研机构的学者也在积极为民间地方 马品种保种工作提供科普和繁育技术支持。

\section{参考文献}

Achilli A, Olivieri A, Soares P, Lancioni H, Kashani BH, Perego UA, Nergadze SG, Carossa V, Santagostino M, Capomaccio S, Felicetti M, Al-Achkar W, Penedo MCT, Verini-Supplizi A, Houshmand M, Woodward SR, Semino O, Silvestrelli M, Giulotto E, Pereira L, Bandelt HJ, Torroni A (2012) Mitochondrial genomes from modern horses reveal the major haplogroups that underwent domestication. Proceedings of the National Academy of Sciences, USA, 109, 2449-2454.

AHC (American Horse Council) (2017) Economic Impact Study of the U.S. Horse Industry. https://www.horsecouncil. org/product/2017-economic-impact-study-u-s-horse-industry (accessed on 2019-12-20)

Allentoft ME, Sikora M, Sjogren KG, Rasmussen S, Rasmussen M, Stenderup J, Damgaard PB, Schroeder H, Ahlstrom T, Vinner L, Malaspinas AS, Margaryan A, Higham T, Chivall D, Lynnerup N, Harvig L, Baron J, Della Casa P, Dabrowski P, Duffy PR, Ebel AV, Epimakhov A, Frei K, Furmanek M, Gralak T, Gromov A, Gronkiewicz S, Grupe G, Hajdu T, Jarysz R, Khartanovich V, Khokhlov A, Kiss V, Kolar J, Kriiska A, Lasak I, Longhi C, McGlynn G, Merkevicius A, Merkyte I, Metspalu M, Mkrtchyan R, Moiseyev V, Paja L, Palfi G, Pokutta D, Pospieszny L, Price TD, Saag L, Sablin M, Shishlina N, Smrcka V, Soenov VI, Szeverenyi V, Toth G, Trifanova SV, Varul L, Vicze M, Yepiskoposyan L, Zhitenev V, Orlando L, Sicheritz-Ponten T, Brunak S, Nielsen R, Kristiansen K, Willerslev E (2015) Population 
genomics of Bronze Age Eurasia. Nature, 522, 167-172.

Andersson LS, Larhammar M, Memic F, Wootz H, Schwochow D, Rubin CJ, Patra K, Arnason T, Wellbring L, Hjälm G (2012) Mutations in DMRT3 affect locomotion in horses and spinal circuit function in mice. Nature, 488, 642-646.

Anthony DW (2010) The Horse, the Wheel, and Language: How Bronze-Age Riders from the Eurasian Steppes Shaped the Modern World. Princeton University Press, Princeton.

Anthony DW, Brown DR (2000) Eneolithic horse exploitation in the Eurasian steppes: Diet, ritual and riding. Antiquity, 74, 75-86.

Anthony DW, Brown DR (2011) The secondary products revolution, horse-riding, and mounted warfare. Journal of World Prehistory, 24, 131-160.

Anthony DW, Telegin DY, Brown D (1991) The origin of horseback riding. Scientific American, 265, 94-101.

Bendrey R (2011) Identification of metal residues associated with bit-use on prehistoric horse teeth by scanning electron microscopy with energy dispersive X-ray microanalysis. Journal of Archaeological Science, 38, 2989-2994.

Bendry R (2010) The horse. In: Extinctions and Invasions: A Social History of British Fauna (eds O’Connor T, Sykes N), pp. 10-16. Windgather Press, Oxford.

Binns M, Boehler D, Lambert D (2010) Identification of the myostatin locus (MSTN) as having a major effect on optimum racing distance in the Thoroughbred horse in the USA. Animal Genetics, 41, 154-158.

Chamberlain JE (2006) Horse: How the Horse Has Shaped Civilizations. BlueBridge Press, New York.

Chysyma R, Khrabrova L, Zaitsev A, Makarova EY, Fedorov YN, Ludu B (2017) Genetic diversity in Tyva horses derived from polymorphism of blood systems and microsatellite DNA. Agricultural Biology, 52, 679-685.

Cieslak M, Pruvost M, Benecke N, Hofreiter M, Morales A, Reissmann M, Ludwig A (2010) Origin and history of mitochondrial DNA lineages in domestic horses. PLoS ONE, 5, e15311.

Darwin C (1859) On the Origin of Species by Means of Natural Selection or the Preservation of Favoured Races in the Struggle for Life. Oxford University Press, London.

Darwin C (1868) The Variation of Animals and Plants Under Domestication. Cambridge University Press, London.

de Barros DP, Martiniano R, Kamm J, Moreno-Mayar JV, Kroonen G, Peyrot M, Barjamovic G, Rasmussen S, Zacho C, Baimukhanov N, Zaibert V, Merz V, Biddanda A, Merz I, Loman V, Evdokimov V, Usmanova E, Hemphill B, Seguin-Orlando A, Yediay FE, Ullah I, Sjogren KG, Iversen $\mathrm{KH}$, Choin J, de la Fuente C, Ilardo M, Schroeder H, Moiseyev V, Gromov A, Polyakov A, Omura S, Senyurt SY, Ahmad H, McKenzie C, Margaryan A, Hameed A, Samad A, Gul N, Khokhar MH, Goriunova OI, Bazaliiskii VI, Novembre J, Weber AW, Orlando L, Allentoft ME, Nielsen R, Kristiansen K, Sikora M, Outram AK, Durbin R,
Willerslev E (2018) The first horse herders and the impact of early Bronze Age steppe expansions into Asia. Science, 360, eaar7711.

Der Sarkissian C, Ermini L, Schubert M, Yang MA, Librado P, Fumagalli M, Jónsson H, Bar-Gal GK, Albrechtsen A, Vieira FG (2015) Evolutionary genomics and conservation of the endangered Przewalski's horse. Current Biology, 25, 2577-2583.

Dorji J, Tamang S, Tshewang T, Dorji T, Dorji TY (2018) Genetic diversity and population structure of three traditional horse breeds of Bhutan based on 29 DNA microsatellite markers. PLoS ONE, 13, e0199376.

Fages A, Hanghoj K, Khan N, Gaunitz C, Seguin-Orlando A, Leonardi M, McCrory Constantz C, Gamba C, Al-Rasheid KAS, Albizuri S, Alfarhan AH, Allentoft M, Alquraishi S, Anthony D, Baimukhanov N, Barrett JH, Bayarsaikhan J, Benecke N, Bernaldez-Sanchez E, Berrocal-Rangel L, Biglari F, Boessenkool S, Boldgiv B, Brem G, Brown D, Burger J, Crubezy E, Daugnora L, Davoudi H, de Barros Damgaard P, de los Ángeles de Chorro y de Villa-Ceballos, M, Deschler-Erb S, Detry C, Dill N, do Mar Oom M, Dohr A, Ellingvag S, Erdenebaatar D, Fathi H, Felkel S, Fernandez-Rodriguez C, Garcia-Vinas E, Germonpre M, Granado JD, Hallsson JH, Hemmer H, Hofreiter M, Kasparov A, Khasanov M, Khazaeli R, Kosintsev P, Kristiansen K, Kubatbek T, Kuderna L, Kuznetsov P, Laleh H, Leonard JA, Lhuillier J, Liesau von Lettow-Vorbeck C, Logvin A, Lougas L, Ludwig A, Luis C, Arruda AM, Marques-Bonet T, Matoso Silva R, Merz V, Mijiddorj E, Miller BK, Monchalov O, Mohaseb FA, Morales A, Nieto-Espinet A, Nistelberger H, Onar V, Palsdottir AH, Pitulko V, Pitskhelauri K, Pruvost M, Rajic Sikanjic P, Rapan Papesa A, Roslyakova N, Sardari A, Sauer E, Schafberg R, Scheu A, Schibler J, Schlumbaum A, Serrand N, Serres-Armero A, Shapiro B, Sheikhi Seno S, Shevnina I, Shidrang S, Southon J, Star B, Sykes N, Taheri K, Taylor W, Teegen WR, Trbojevic Vukicevic T, Trixl S, Tumen D, Undrakhbold S, Usmanova E, Vahdati A, Valenzuela-Lamas S, Viegas C, Wallner B, Weinstock J, Zaibert V, Clavel B, Lepetz S, Mashkour M, Helgason A, Stefansson K, Barrey E, Willerslev E, Outram AK, Librado P, Orlando L (2019) Tracking five millennia of horse management with extensive ancient genome time series. Cell, 177, 1419-1435.

FAO (2015) The Second Report on the State of the World's Animal Genetic Resources for Food and Agriculture. FAO Commission on Genetic Resources for Food and Agriculture Assessments, Rome.

FAO (2017) Domestic Animal Diversity Information System (DAD-IS). http://www.fao.org/dad-is/data/en/ (accessed on 2019-10-17)

Felkel S, Vogl C, Rigler D, Dobretsberger V, Chowdhary BP, Distl O, Fries R, Jagannathan V, Janecka JE, Leeb T, Lindgren G, McCue M, Metzger J, Neuditschko M, Rattei T, 
Raudsepp T, Rieder S, Rubin CJ, Schaefer R, Schlotterer C, Thaller G, Tetens J, Velie B, Brem G, Wallner B (2019) The horse $\mathrm{Y}$ chromosome as an informative marker for tracing sire lines. Scientific Reports, 9, 1-12.

Felkel S, Vogl C, Rigler D, Jagannathan V, Leeb T, Fries R, Neuditschko M, Rieder S, Velie B, Lindgren G, Rubin CJ, Schlotterer C, Rattei T, Brem G, Wallner B (2018) Asian horses deepen the MSY phylogeny. Animal Genetics, 49, 90-93.

Gaunitz C, Fages A, Hanghoj K, Albrechtsen A, Khan N, Schubert M, Seguin-Orlando A, Owens IJ, Felkel S, Bignon-Lau O, Damgaard PD, Mittnik A, Mohaseb AF, Davoudi H, Alquraishi S, Alfarhan AH, Al-Rasheid KAS, Crubezy E, Benecke N, Olsen S, Brown D, Anthony D, Massy K, Pitulko V, Kasparov A, Brem G, Hofreiter M, Mukhtarova G, Baimukhanov N, Lougas L, Onar V, Stockhammer PW, Krause J, Boldgiv B, Undrakhbold S, Erdenebaatar D, Lepetz S, Mashkour M, Ludwig A, Wallner B, Merz V, Merz I, Zaibert V, Willerslev E, Librado P, Outram AK, Orlando L (2018) Ancient genomes revisit the ancestry of domestic and Przewalski's horses. Science, 360, 111-114.

Groves C, Grubb P (2011) Ungulate Taxonomy. The Johns Hopkins University Press, Baltimore.

Han H, Wallner B, Rigler D, MacHugh DE, Manglai D, Hill EW (2019) Chinese Mongolian horses may retain early domestic male genetic lineages yet to be discovered. Animal Genetics, 50, 399-402.

Hanks B (2010) Archaeology of the Eurasian steppes and Mongolia. Annual Review of Anthropology, 39, 469-486.

Hewitt G (2000) The genetic legacy of the Quaternary ice ages. Nature, 405, 907-913.

Hill EW, Bradley DG, Al-Barody M, Ertugrul O, Splan RK, Zakharov I, Cunningham EP (2002) History and integrity of thoroughbred dam lines revealed in equine mtDNA variation. Animal Genetics, 33, 287-294.

Hill EW, Gu J, Eivers SS, Fonseca RG, McGivney BA, Govindarajan P, Orr N, Katz LM, MacHugh D (2010a) A sequence polymorphism in MSTN predicts sprinting ability and racing stamina in thoroughbred horses. PLoS ONE, 5, e8645.

Hill EW, Gu J, McGivney BA, MacHugh D (2010b) Targets of selection in the Thoroughbred genome contain exerciserelevant gene SNPs associated with elite racecourse performance. Animal Genetics, 41, 56-63.

Holgate SA (2018) Outside the Research Lab, Volume 2: Physics in Vintage and Modern Transport. Morgan \& Claypool Publishers, San Rafael, CA.

Hunter P (2018) The genetics of domestication: Research into the domestication of livestock and companion animals sheds light both on their "evolution" and human history. EMBO Reports, 19, 201-205.

Jäderkvist K, Holm N, Imsland F, Árnason T, Andersson L,
Andersson LS, Lindgren G (2015) The importance of the DMRT3 'Gait keeper' mutation on riding traits and gaits in Standardbred and Icelandic horses. Livestock Science, 176, 33-39.

Jansen T, Forster P, Levine MA, Oelke H, Hurles M, Renfrew C, Weber J, Olek K (2002) Mitochondrial DNA and the origins of the domestic horse. Proceedings of the National Academy of Sciences, USA, 99, 10905-10910.

Jun J, Cho YS, Hu H, Kim HM, Jho S, Gadhvi P, Park KM, Lim J, Paek WK, Han K, Manica A, Edwards JS, Bhak J (2014) Whole genome sequence and analysis of the Marwari horse breed and its genetic origin. BMC Genomics, 15 (Suppl. 9), S4.

Kader A, Li Y, Dong K, Irwin DM, Zhao Q, He X, Liu J, Pu Y, Gorkhali NA, Liu X (2015) Population variation reveals independent selection toward small body size in Chinese Debao pony. Genome Biology and Evolution, 8, 42-50.

Kalbfleisch TS, Rice E, DePriest MS, Walenz BP, Hestand MS, Vermeesch JR, O’Connell BL, Fiddes IT, Vershinina AO, Petersen JL (2018) EquCab3, an updated reference genome for the domestic horse. BioRxiv, 306928.

Khanshour A, Conant E, Juras R, Cothran EG (2013) Microsatellite analysis of genetic diversity and population structure of Arabian horse populations. Journal of Heredity, 104, 386-398.

Kristjansson T, Bjornsdottir S, Sigurdsson A, Andersson L, Lindgren G, Helyar S, Klonowski A, Arnason T (2014) The effect of the 'Gait keeper' mutation in the DMRT3 gene on gaiting ability in Icelandic horses. Journal of Animal Breeding and Genetics, 131, 415-425.

Larson G, Karlsson EK, Perri A, Webster MT, Ho SY, Peters J, Stahl PW, Piper PJ, Lingaas F, Fredholm M, Comstock KE, Modiano JF, Schelling C, Agoulnik AI, Leegwater PA, Dobney K, Vigne JD, Vilà C, Andersson L, Lindblad-Toh K (2012) Rethinking dog domestication by integrating genetics, archeology, and biogeography. Proceedings of the National Academy of Sciences, USA, 109, 8878-8883.

Lei ZH, Gao C (2014) Study on the posture of Bronze Running Horse. Studies on Philosophy of Science and Technology, 31(6), 81-86. (in Chinese) [雷志华, 高策 (2014) 铜奔马 姿势的研究. 科学技术哲学, 31(6), 81-86.]

Levine MA (1990) Dereivka and the problem of horse domestication. Antiquity, 64, 727-740.

Levine MA (2005) Domestication and early history of the horse. In: Domestic Horse: The Origins, Development and Management of Its Behaviour, pp. 5-22. Cambridge University Press, Cambridge.

Librado P, Fages A, Gaunitz C, Leonardi M, Wagner S, Khan N, Hanghoj K, Alquraishi SA, Alfarhan AH, Al-Rasheid KA, Der Sarkissian C, Schubert M, Orlando L (2016) The evolutionary origin and genetic makeup of domestic horses. Genetics, 204, 423-434.

Librado P, Gamba C, Gaunitz C, Der Sarkissian C, Pruvost M, 
Albrechtsen A, Fages A, Khan N, Schubert M, Jagannathan V, Serres-Armero A, Kuderna LFK, Povolotskaya IS, Seguin-Orlando A, Lepetz S, Neuditschko M, Theves C, Alquraishi S, Alfarhan AH, Al-Rasheid K, Rieder S, Samashev Z, Francfort HP, Benecke N, Hofreiter M, Ludwig A, Keyser C, Marques-Bonet T, Ludes B, Crubezy E, Leeb T, Willerslev E, Orlando L (2017) Ancient genomic changes associated with domestication of the horse. Science, 356, 442-445.

Librado P, Sarkissian CD, Ermini L, Schubert M, Jonsson H, Albrechtsen A, Fumagalli M, Yang MA, Gambo C, Seguin-Orlando A, Mortensen CD, Petersen B, Hoover CA, Lorente-Galdos B, Nedoluzhko A, Boulygina E, Tsygankova S, Neuditschko M, Jagannathan V, Theves C, Alfarhan AH, Alquraishi SA, Al-Rasheid KAS, Sicheritz-Ponten T, Popov R, Grigoriev S, Alekseev AN, Rubin EM, McCue M, Rieder S, Leeb T, Tikhonov A, Crubezy E, Slatkin M, Marques-Bonet $\mathrm{T}$, Nielsen R, Willerslev E, Kantanen J, Prokhortchouk E, Orlando L (2015) Tracking the origins of Yakutian horses and the genetic basis for their fast adaptation to subarctic environments. Proceedings of the National Academy of Sciences, USA, 112, 6889-6897.

Lindgren G, Backstrom N, Swinburne J, Hellborg L, Einarsson A, Sandberg K, Cothran G, Vila C, Binns M, Ellegren H (2004) Limited number of patrilines in horse domestication. Nature Genetics, 36, 335-336.

Ling YH, Ma YH, Guan WJ, Cheng YJ, Wang YP, Han JL, Mang L, Zhao QJ, He XH, Pu YB, Fu BL (2011) Evaluation of the genetic diversity and population structure of Chinese indigenous horse breeds using 27 microsatellite markers. Animal Genetics, 42, 56-65.

Lippold S, Knapp M, Kuznetsova T, Leonard JA, Benecke N, Ludwig A, Rasmussen M, Cooper A, Weinstock J, Willerslev E, Shapiro B, Hofreiter M (2011a) Discovery of lost diversity of paternal horse lineages using ancient DNA. Nature Communications, 2, 450.

Lippold S, Matzke NJ, Reissmann M, Hofreiter M (2011b) Whole mitochondrial genome sequencing of domestic horses reveals incorporation of extensive wild horse diversity during domestication. BMC Evolutionary Biology, 11, 328.

Lira J, Linderholm A, Olaria C, Brandstrom Durling M, Gilbert MT, Ellegren H, Willerslev E, Liden K, Arsuaga JL, Gotherstrom A (2010) Ancient DNA reveals traces of Iberian Neolithic and Bronze Age lineages in modern Iberian horses. Molecular Ecology, 19, 64-78.

Liu X, Zhang Y, Li Y, Pan J, Wang D, Chen W, Zheng Z, He X, Zhao Q, Pu Y, Guan W, Han J, Orlando L, Ma Y, Jiang L (2019) EPAS1 gain-of-function mutation contributes to highaltitude adaptation in Tibetan horses. Molecular Biology and Evolution, 19, 1655.

Lopes MS, Mendonca D, Cymbron T, Valera M, da Costa-Ferreira J, Machado AD (2005) The Lusitano horse maternal lineage based on mitochondrial D-loop sequence variation. Animal Genetics, 36, 196-202.

Ludwig A, Pruvost M, Reissmann M, Benecke N, Brockmann GA, Castanos P, Cieslak M, Lippold S, Llorente L, Malaspinas AS, Slatkin M, Hofreiter M (2009) Coat color variation at the beginning of horse domestication. Science, 324, 485 .

Luis C, Bastos-Silveira C, Cothran EG, Oom M (2006) Iberian origins of New World horse breeds. Journal of Heredity, 97, 107-113.

Luis C, Juras R, Oom M, Cothran E (2007) Genetic diversity and relationships of Portuguese and other horse breeds based on protein and microsatellite loci variation. Animal Genetics, 38, 20-27.

Makvandi-Nejad S, Hoffman GE, Allen JJ, Chu E, Gu E, Chandler AM, Loredo AI, Bellone RR, Mezey JG, Brooks SA (2012) Four loci explain $83 \%$ of size variation in the horse. PLoS ONE, 7, e39929.

McCoy AM, Schaefer R, Petersen JL, Morrell PL, Slamka MA, Mickelson JR, Valberg SJ, McCue ME (2013) Evidence of positive selection for a glycogen synthase (GYS1) mutation in domestic horse populations. Journal of Heredity, 105, 163-172.

McCue ME, Bannasch DL, Petersen JL, Gurr J, Bailey E, Binns MM, Distl O, Guerin G, Hasegawa T, Hill EW, Leeb T, Lindgren G, Penedo MC, Roed KH, Ryder OA, Swinburne JE, Tozaki T, Valberg SJ, Vaudin M, Lindblad-Toh K, Wade CM, Mickelson JR (2012) A high density SNP array for the domestic horse and extant Perissodactyla: Utility for association mapping, genetic diversity, and phylogeny studies. PLoS Genetics, 8, e1002451.

McCue ME, Valberg SJ, Miller MB, Wade C, DiMauro S, Akman HO, Mickelson JR (2008) Glycogen synthase (GYS1) mutation causes a novel skeletal muscle glycogenosis. Genomics, 91, 458-466.

Mileto S, Kaiser E, Rassamakin Y, Evershed RP (2017) New insights into the subsistence economy of the Eneolithic Dereivka culture of the Ukrainian North-Pontic region through lipid residues analysis of pottery vessels. Journal of Archaeological Science: Reports, 13, 67-74.

Moyers BT, Morrell PL, McKay JK (2017) Genetic costs of domestication and improvement. Journal of Heredity, 109, 103-116.

Oldenbroek JK (1999) Genebanks and the Management of Farm Animal Genetic Resources. DLO Institute for Animal Sciences and Health, Lelystad.

Orlando L, Ginolhac A, Zhang G, Froese D, Albrechtsen A, Stiller M, Schubert M, Cappellini E, Petersen B, Moltke I, Johnson PL, Fumagalli M, Vilstrup JT, Raghavan M, Korneliussen T, Malaspinas AS, Vogt J, Szklarczyk D, Kelstrup CD, Vinther J, Dolocan A, Stenderup J, Velazquez AM, Cahill J, Rasmussen M, Wang X, Min J, Zazula GD, Seguin-Orlando A, Mortensen C, Magnussen K, Thompson JF, Weinstock J, Gregersen K, Roed KH, Eisenmann V, 
Rubin CJ, Miller DC, Antczak DF, Bertelsen MF, Brunak S, Al-Rasheid KA, Ryder O, Andersson L, Mundy J, Krogh A, Gilbert MT, Kjaer K, Sicheritz-Ponten T, Jensen LJ, Olsen JV, Hofreiter M, Nielsen R, Shapiro B, Wang J, Willerslev E (2013) Recalibrating Equus evolution using the genome sequence of an early Middle Pleistocene horse. Nature, 499, 74-78.

Orlando L, Librado P (2019) Origin and evolution of deleterious mutations in horses. Genes (Basel), 10, 649.

Orr N, Back W, Gu J, Leegwater P, Govindarajan P, Conroy J, Ducro B, Van Arendonk J, MacHugh D, Ennis S (2010) Genome-wide SNP association-based localization of a dwarfism gene in Friesian dwarf horses. Animal Genetics, 41, 2-7.

Outram AK, Stear NA, Bendrey R, Olsen S, Kasparov A, Zaibert V, Thorpe N, Evershed RP (2009) The earliest horse harnessing and milking. Science, 323, 1332-1335.

Petersen JL, Mickelson JR, Cothran EG, Andersson LS, Axelsson J, Bailey E, Bannasch D, Binns MM, Borges AS, Brama P, da Camara Machado A, Distl O, Felicetti M, Fox-Clipsham L, Graves KT, Guerin G, Haase B, Hasegawa T, Hemmann K, Hill EW, Leeb T, Lindgren G, Lohi H, Lopes MS, McGivney BA, Mikko S, Orr N, Penedo MC, Piercy RJ, Raekallio M, Rieder S, Roed KH, Silvestrelli M, Swinburne J, Tozaki T, Vaudin M, Wade C, McCue ME (2013a) Genetic diversity in the modern horse illustrated from genome-wide SNP data. PLoS ONE, 8, e54997.

Petersen JL, Mickelson JR, Rendahl AK, Valberg SJ, Andersson LS, Axelsson J, Bailey E, Bannasch D, Binns MM, Borges AS (2013b) Genome-wide analysis reveals selection for important traits in domestic horse breeds. PLoS Genetics, 9, e1003211.

Primack RB, Ma KP (2009) A Primer of Conservation Biology. Higher Education Press, Beijing. (in Chinese) [Primack RB, 马克平 (2009) 保护生物学简明教程. 高等教育出版社, 北京.]

Promerová M, Andersson L, Juras R, Penedo M, Reissmann M, Tozaki T, Bellone R, Dunner S, Hořín P, Imsland F (2014) Worldwide frequency distribution of the "Gait keeper" mutation in the DMRT3 gene. Animal Genetics, 45, 274-282.

Pruvost M, Bellone R, Benecke N, Sandoval-Castellanos E, Cieslak M, Kuznetsova T, Morales-Muniz A, O’Connor T, Reissmann M, Hofreiter M, Ludwig A (2011) Genotypes of predomestic horses match phenotypes painted in Paleolithic works of cave art. Proceedings of the National Academy of Sciences, USA, 108, 18626-18630.

Rege JEO, Gibson JP (2003) Animal genetic resources and economic development: Issues in relation to economic valuation. Ecological Economics, 45, 319-330.

Ricard A (2015) Does heterozygosity at the DMRT3 gene make French trotters better racers? Genetics Selection Evolution, 47, 1-16.

Royo LJ, Alvarez I, Beja-Pereira A, Molina A, Fernandez I,
Jordana J, Gomez E, Gutierrez JP, Goyache F (2005) The origins of Iberian horses assessed via mitochondrial DNA. Journal of Heredity, 96, 663-669.

Sandoval-Castellanos E, Wutke S, Gonzalez-Salazar C, Ludwig A (2017) Coat colour adaptation of post-glacial horses to increasing forest vegetation. Nature Ecology \& Evolution, 1, 1816-1819.

Sarkissian CD, Ermini L, Schubert M, Yang MA, Librado P, Fumagalli M, Jonsson H, Bar-Gal GK, Albrechtsen A, Vieira FG, Petersen B, Ginolhac A, Seguin-Orlando A, Magnussen K, Fages A, Gamba C, Lorente-Galdos B, Polani S, Steiner C, Neuditschko M, Jagannathan V, Feh C, Greenblatt CL, Ludwig A, Abramson NI, Zimmermann W, Schafberg R, Tikhonov A, Sicheritz-Ponten T, Willerslev E, Marques-Bonet T, Ryder OA, Mccue M, Rieder S, Leeb T, Slatkin M, Orlando L (2015) Evolutionary Genomics and Conservation of the Endangered Przewalski's Horse. Current Biology, 25, 2577-2583.

Schröder W, Klostermann A, Stock K, Distl O (2012) A genome-wide association study for quantitative trait loci of show-jumping in Hanoverian warmblood horses. Animal Genetics, 43, 392-400.

Schubert M, Jonsson H, Chang D, Der Sarkissian C, Ermini L, Ginolhac A, Albrechtsen A, Dupanloup I, Foucal A, Petersen B, Fumagalli M, Raghavan M, Seguin-Orlando A, Korneliussen TS, Velazquez AM, Stenderup J, Hoover CA, Rubin CJ, Alfarhan AH, Alquraishi SA, Al-Rasheid KA, MacHugh DE, Kalbfleisch T, MacLeod JN, Rubin EM, Sicheritz-Ponten T, Andersson L, Hofreiter M, MarquesBonet T, Gilbert MT, Nielsen R, Excoffier L, Willerslev E, Shapiro B, Orlando L (2014) Prehistoric genomes reveal the genetic foundation and cost of horse domestication. Proceedings of the National Academy of Sciences, USA, 111, 5661-5669.

Signer-Hasler H, Flury C, Haase B, Burger D, Simianer H, Leeb T, Rieder S (2012) A genome-wide association study reveals loci influencing height and other conformation traits in horses. PLoS ONE, 7, e37282.

Sommer RS, Benecke N, Lougas L, Nelle O, Schmolcke U (2011) Holocene survival of the wild horse in Europe: A matter of open landscape? Journal of Quaternary Science, 26, 805-812.

Thurtle P (2011) The Emergence of Genetic Rationality: Space, Time, and Information in American Biological Science, 1870-1920. University of Washington Press, Seattle.

Tozaki T, Kikuchi M, Kakoi H, Hirota K, Nagata S, Yamashita D, Ohnuma T, Takasu M, Kobayashi I, Hobo S, Manglai D, Petersen JL (2019) Genetic diversity and relationships among native Japanese horse breeds, the Japanese Thoroughbred and horses outside of Japan using genome-wide SNP data. Animal Genetics, 50, 449-459.

Tozaki T, Takezaki N, Hasegawa T, Ishida N, Kurosawa M, Tomita M, Saitou N, Mukoyama H (2003) Microsatellite 
variation in Japanese and Asian horses and their phylogenetic relationship using a European horse outgroup. Journal of Heredity, 94, 374-380.

Trut L, Oskina I, Kharlamova A (2009) Animal evolution during domestication: The domesticated fox as a model. Bioessays, 31, 349-360.

Vila C, Leonard JA, Gotherstrom A, Marklund S, Sandberg K, Liden K, Wayne RK, Ellegren H (2001) Widespread origins of domestic horse lineages. Science, 291, 474-477.

Wallner B, Palmieri N, Vogl C, Rigler D, Bozlak E, Druml T, Jagannathan V, Leeb $T$, Fries R, Tetens J, Thaller G, Metzger J, Distl O, Lindgren G, Rubin CJ, Andersson L, Schaefer R, McCue M, Neuditschko M, Rieder S, Schlotterer C, Brem G (2017) Y chromosome uncovers the recent oriental origin of modern stallions. Current Biology, 27, 2029-2035.

Wallner B, Vogl C, Shukla P, Burgstaller JP, Druml T, Brem G (2013) Identification of genetic variation on the horse $Y$ chromosome and the tracing of male founder lineages in modern breeds. PLoS ONE, 8, e60015.

Wan X (2013) The Horse in Pre-Imperial China. PhD dissertation, University of Pennsylvania, Philadelphia.

Warmuth V, Eriksson A, Bower MA, Barker G, Barrett E,
Hanks BK, Li S, Lomitashvili D, Ochir-Goryaeva M, Sizonov GV, Soyonov V, Manica A (2012) Reconstructing the origin and spread of horse domestication in the Eurasian steppe. Proceedings of the National Academy of Sciences, USA, 109, 8202-8206.

Warmuth V, Eriksson A, Bower MA, Canon J, Cothran G, Distl O, Glowatzki-Mullis ML, Hunt H, Luis C, do Mar Oom M, Yupanqui IT, Zabek T, Manica A (2011) European domestic horses originated in two holocene refugia. PLoS ONE, 6, e18194.

Yang Y, Zhu Q, Liu S, Zhao C, Wu C (2017) The origin of Chinese domestic horses revealed with novel mtDNA variants. Animal Science Journal, 88, 19-26.

Zhao RY, Zhao YP, Li B, Bou G, Zhang XZ, Mongke T, Bao T, Gereliin S, Gereltuuin T, Li C, Bai DY, Dugarjaviin ML (2018) Overview of the genetic control of horse coat color patterns. Hereditas (Beijing), 40, 357-368. (in Chinese with English abstract) [赵若阳, 赵一萍, 李蓓, 格日乐其木格, 张心壮, 陶克涛, 图格琴, 旭仁其木格, 青柏, 李超, 白 东义, 芒来 (2018) 马毛色遗传机理研究进展. 遗传, 40, 357-368.]

(责任编委: 王文 责任编辑: 时意专)

\section{附录 Supplementary Material}

\section{附录1 家马SNP标记遗传多样性研究汇总}

Appendix 1 Summary of SNP Marker studies on genetic diversity of domestic horses http://www.biodiversity-science.net/fileup/PDF/2020005-1.pdf

附录 2 家马 SSR 标记遗传多样性研究汇总

Appendix 2 Summary of SSR Marker studies on genetic diversity of domestic horses http://www.biodiversity-science.net/fileup/PDF/2020005-2.pdf 
陶克涛, 韩海格, 赵若阳, 图格琴, 芒来, 白东义. 家马的驯化起源与遗传演化特征.生物多样性, 2020, 28 (6): 734-748. http://www.biodiversity-science.net/fileup/PDF/2020005

附录 1 家马 SNP 标记遗传多样性研究汇总 Appendix 1 Summary of SNP Marker studies on genetic diversity of domestic horses

\begin{tabular}{|c|c|c|c|c|}
\hline 芯片类型 & 品种(数) & 地区 & 研究结果 & 参考文献 \\
\hline Chip type & Breed & Region & Research results & References \\
\hline Illumina & 纯血马 & 英国 & 在 1961-2006 年间, 纯血马近交系数呈增 & Binns et al, \\
\hline Equine SNP50 & Thoroughbreds & UK & 加的趋势, 而此趋势主要发生在 1996 年之 & 2012 \\
\hline \multirow[t]{20}{*}{ BeadChip } & & & 后, 1995 年之前, 近交系数的变化并不显 & \\
\hline & & & 著。 & \\
\hline & 纯血马、夸特 & 欧亚北美 & 蒙古马遗传多样性最丰富,纯血马最低; LD & McCue et al, \\
\hline & 马、蒙古马等 & Eurasia, North & 纯血马最高, 蒙古马和夸特马最低; 近交 & 2012 \\
\hline & 14 个品种 & America & 系数纯血马和标准马最高, 蒙古马、汉诺 & \\
\hline & 14 breeds & & 威马和夸特马最低; 遗传距离在挪威峡湾 & \\
\hline & including & & 马和冰岛马中最低, 在汉诺威马、夸特马和 & \\
\hline & Thoroughbreds, & & 瑞士温血马中最高; 系统发育树分析将现 & \\
\hline & Quarter horse, & & 代家马与普氏野马分为姊妹两类。 & \\
\hline & Mongolian horse & & & \\
\hline & 夸特马 & 美国 & 速度赛夸特马的体重、体高、体长和管围 & Meira et al, \\
\hline & Quarter horse & USA & 等体尺指标均高于截牛赛夸特马; 速度赛 & 2013 \\
\hline & & & 夸特马近交系数高于截牛赛夸特马, 速度 & \\
\hline & & & 赛夸特马可能受到了更高程度的近亲繁殖 & \\
\hline & & & 及选择压力。 & \\
\hline & 蒙古马等 36 个 & 欧亚 & 高选择压力、封闭育种种群、遗传瓶颈和 & Petersen et al, \\
\hline & 品种 & Eurasia & 种群数量少的品种具有低遗传多样性, 低 & 2013 \\
\hline & 36 horse breeds & & 选择压力、种内表型丰富、开放育种种群 & \\
\hline & including & & 的品种具有高遗传多样性。 & \\
\hline & Mongolian horse & & & \\
\hline Illumina & 济州马、 & 韩国 & 纯血马 LD 最高, 济州马最低; 济州杂种 & Kim et al, \\
\hline Equine SNP70 & 纯血马、济州杂 & South Korea & 马与纯血马的遗传相似性高于济州马; 期 & 2018 \\
\hline \multirow[t]{15}{*}{ BeadChip } & 种马(济州马 $\times$ & & 望杂合度济州杂种马最高, 随之纯血马, & \\
\hline & 纯血马) & & 济州马最低; 近交程度纯血马最高, 济州 & \\
\hline & Jeju horse, & & 马最低; 济州马与纯血马的分化程度最高。 & \\
\hline & Thoroughbreds, & & & \\
\hline & Jeju cross-breed & & & \\
\hline & horse (Jeju horse & & & \\
\hline & $x$ & & & \\
\hline & Thoroughbreds) & & & \\
\hline & 8 个日本地方马 & 日本 & 日本地方马品种遗传多样低并且近交程度 & Tozaki et al, \\
\hline & 品种、日本纯血 & Japan & 高; 日本地方品种可分为日本主岛支系和 & 2019 \\
\hline & 马 & & 南岛支系两支; 日本纯血马遗传多样性与 & \\
\hline & 8 native Japanese & & 欧美纯血马相似; 日本地方马品种与蒙古 & \\
\hline & horse breeds, & & 马可能来自于相同的祖先。 & \\
\hline & Japanese & & & \\
\hline & Thoroughbreds & & & \\
\hline
\end{tabular}


陶克涛，韩海格，赵若阳，图格琴，芒来，白东义. 家马的驯化起源与遗传演化特征.生物多样性, 2020, 28 (6): 734-748. http://www.biodiversity-science.net/fileup/PDF/2020005

\begin{tabular}{|c|c|c|c|c|}
\hline 芯片类型 & 品种(数) & 地区 & 研究结果 & 参考文献 \\
\hline Chip type & Breed & Region & Research results & References \\
\hline $670 \mathrm{k}$ & 波斯尼亚山马、 & 欧洲 & 波斯尼亚山马分化程度最高；波斯尼亚山 & Grilz-Seger et \\
\hline Affymetrix & 波萨维马、斯洛 & Europe & 马和斯洛文尼亚哈福林格马具有高 & al, 2018 \\
\hline Axiom Equine & 文尼亚哈福林格 & & $\mathrm{SROH} / \mathrm{FROH}$ 值和较长的 ROHs, 表示此品 & \\
\hline genotyping & 马 & & 种正经历瓶颈效应和近亲繁殖。相反, 波 & \\
\hline \multirow[t]{21}{*}{ array } & Bosnian & & 萨维马 $\mathrm{ROH}$ 参数较低, 近期的近交繁殖程 & \\
\hline & mountain horse, & & 度较低。 & \\
\hline & Posavje horse, & & & \\
\hline & Slovenia & & & \\
\hline & Haflinger & & & \\
\hline & 波斯阿拉伯马、 & 中东 & 波斯阿拉伯马和其它伊朗地方品种之间遗 & Sadeghi et al, \\
\hline & 伊朗地方马 & Middle East & 传结构独立, 并且波斯阿拉伯马可细分为 & 2019 \\
\hline & Persian Arabian & & 三个支; 波斯阿拉伯马近交程度较低, 但 & \\
\hline & horse, native & & 其有效群体大小呈下降趋势。 & \\
\hline & Iranian horse & & & \\
\hline & breeds & & & \\
\hline & 利皮扎马 & 欧洲 & 奥地利利皮扎马种群的遗传距离较近, 除 & Grilz-Seger et \\
\hline & Lipizzan horse & Europe & 少数外来引入个体外总体血缘关系很近。 & al, 2019 \\
\hline & & & 而克罗地亚, 匈牙利和斯洛伐克利皮扎马 & \\
\hline & & & 种群具有高的遗传多样性, 并且相互关联; & \\
\hline & & & 奥地利、克罗地亚和斯洛伐克利皮扎马种 & \\
\hline & & & 群遗传关系较近, 而匈牙利种群较远; 奥 & \\
\hline & & & 地利利皮扎马近交程度最高, 匈牙利利皮 & \\
\hline & & & 扎马最低。匈牙利利皮扎马群体与克罗地 & \\
\hline & & & 亚群体之间以及奥地利和斯洛伐克群体之 & \\
\hline & & & 间遗传关系更为接近。 & \\
\hline
\end{tabular}


陶克涛, 韩海格, 赵若阳, 图格琴, 芒来, 白东义. 家马的驯化起源与遗传演化特征.生物多样性, 2020, 28 (6): 734-748. http://www.biodiversity-science.net/fileup/PDF/2020005

附录 2 家马 SSR 标记遗传多样性研究汇总

Appendix 2 Summary of SSR Marker studies on genetic diversity of domestic horses

\begin{tabular}{|c|c|c|c|}
\hline $\begin{array}{l}\text { 品种(数) } \\
\operatorname{Breed}(\mathrm{s})\end{array}$ & $\begin{array}{l}\text { 地区 } \\
\text { Region }\end{array}$ & $\begin{array}{l}\text { 研究结果 } \\
\text { Research results }\end{array}$ & $\begin{array}{l}\text { 参考文献 } \\
\text { References }\end{array}$ \\
\hline $\begin{array}{l}\text { 日本地方品种 (7) 、 } \\
\text { 蒙古马 } \\
\text { native Japanese breeds (7), } \\
\text { Mongolian horse }\end{array}$ & $\begin{array}{l}\text { 日本群岛、蒙古高原 } \\
\text { Japanese Archipelago, } \\
\text { Mongolian Plateau }\end{array}$ & $\begin{array}{l}\text { 蒙古马的平均杂合度高于日本地方马品 } \\
\text { 种, 并且包含了日本地方马品种所有的 } \\
\text { 等位基因。 }\end{array}$ & $\begin{array}{l}\text { Tozaki et al, } \\
2003\end{array}$ \\
\hline $\begin{array}{l}\text { 利皮扎马 } \\
\text { Lipizzan horse }\end{array}$ & $\begin{array}{l}\text { 奥地利、克罗地亚、意大 } \\
\text { 利、罗马尼亚、斯洛文尼 } \\
\text { 亚、斯洛伐克、匈牙利 } \\
\text { Austria, Croatia, Italy, } \\
\text { Romania, Slovenia, } \\
\text { Slovakia, Hungary }\end{array}$ & $\begin{array}{l}\text { 由于第一次和第二次世界大战后的育种 } \\
\text { 目标和地理及社会政治隔离导致了种内 } \\
\text { 一定程度的分化。 }\end{array}$ & $\begin{array}{l}\text { Achmann et al, } \\
2004\end{array}$ \\
\hline $\begin{array}{l}\text { 加拉诺马、卢西塔诺马、 } \\
\text { 索雷亚马 } \\
\text { Garrano horse, Lusitano } \\
\text { horse, Sorraia horse }\end{array}$ & $\begin{array}{l}\text { 伊比利亚半岛 } \\
\text { Iberian Peninsula }\end{array}$ & $\begin{array}{l}\text { 加拉诺马和卢西塔诺马遗传变异程度较 } \\
\text { 高。濒危品种索雷亚马的遗传变异较 } \\
\text { 低, 这与其来自 } 12 \text { 匹祖先的奠基者效应 } \\
\text { 以及小的有效群体规模有关。 }\end{array}$ & Luis et al, 2007 \\
\hline $\begin{array}{l}\text { 宁强矮马、蒙古马 } \\
\text { Ningqiang horse, } \\
\text { Mongolian horse }\end{array}$ & $\begin{array}{l}\text { 中国 } \\
\text { China }\end{array}$ & $\begin{array}{l}\text { 蒙古马遗传多样性大于宁强矮马, 但品 } \\
\text { 种间遗传关系较近。 }\end{array}$ & Du et al, 2009 \\
\hline $\begin{array}{l}\text { 中国地马品种(26) } \\
\text { native Chinese horse breeds } \\
\text { (26) }\end{array}$ & $\begin{array}{l}\text { 中国 } \\
\text { China }\end{array}$ & $\begin{array}{l}\text { 中国马品种间遗传分化程度较低, 并 } \\
\text { 且, 中国家马可由地理分布归类为江 } \\
\text { 南、青藏高原、东北、西北和内蒙古等 } \\
\text { 五个群体。 }\end{array}$ & Ling et al, 2011 \\
\hline $\begin{array}{l}\text { 马瓦里马、斯皮蒂马、 } \\
\text { 卡提阿瓦马 }\end{array}$ & $\begin{array}{l}\text { 印度 } \\
\text { India }\end{array}$ & $\begin{array}{l}\text { 三个印度品种种间分化和种内近亲繁殖 } \\
\text { 程度较高。数量急剧下降至几千匹的卡 }\end{array}$ & $\begin{array}{l}\text { Chauhan et al, } \\
2011\end{array}$ \\
\hline $\begin{array}{l}\text { Marwari horse, Spiti horse, } \\
\text { Kathiawari horse }\end{array}$ & & $\begin{array}{l}\text { 提阿瓦马和斯皮蒂马可能发生了种群瓶 } \\
\text { 颈效应。 }\end{array}$ & \\
\hline $\begin{array}{l}\text { 胡克尔马 } \\
\text { Hucul horse }\end{array}$ & $\begin{array}{l}\text { 中欧 } \\
\text { Central Europe }\end{array}$ & 胡克尔马遗传变异较高, 近交程度低。 & $\begin{array}{l}\text { Kusza et al, } \\
2013\end{array}$ \\
\hline 阿拉伯马 & 中东 & 中东阿拉伯马群体的遗传多样性高于欧 & Khanshour et al, \\
\hline Arabian horse & $\begin{array}{l}\text { Middle East, } \\
\text { 欧美 } \\
\text { Europe\& Northern America }\end{array}$ & $\begin{array}{l}\text { 美阿拉伯马群体, 且近交程度低。中东 } \\
\text { 阿拉伯马不同种群间遗传分化低, 欧美 } \\
\text { 不同种群间遗传分化高。 }\end{array}$ & 2013 \\
\hline 图瓦马 & 俄罗斯西伯利亚 & 图瓦马具有高遗传多样性和低近交程 & Chysyma et al, \\
\hline Tuva horse & Russian Siberia & $\begin{array}{l}\text { 度。发现了在欧洲马品种中未发现的等 } \\
\text { 位基因 HMS1R。图瓦马与蒙古马和哈萨 } \\
\text { 克马亲缘关系较近。 }\end{array}$ & 2017 \\
\hline 关中马 & 中国 & 关中马遗传多样性较低, 这与自 20 世纪 & Zeng et al, 2019 \\
\hline Guanzhong horse & China & $\begin{array}{l}70 \text { 年代以来实行的种内繁殖及高度近交 } \\
\text { 有关。 }\end{array}$ & \\
\hline 阿哈尔捷金马 & 意大利 & 意大利阿哈尔捷金马具有较高的遗传多 & Cozzi et al, 2018 \\
\hline Akhal-teke horse & Italy & 样性和低近交程度。 & \\
\hline
\end{tabular}


陶克涛，韩海格，赵若阳，图格琴，芒来，白东义. 家马的驯化起源与遗传演化特征.生物多样性, 2020, 28 (6): 734-748. http://www.biodiversity-science.net/fileup/PDF/2020005

\begin{tabular}{llll}
\hline 品种(数) & 地区 & 研究结果 & 参考文献 \\
Breed(s) & Region & Research results & References \\
\hline 布塔马、沙尔塔马、 & 不丹 & 不丹地方马品种遗传多样性丰富, 交程 & Dorji et al, 2018 \\
尤塔马 & Bhutan & 度低。且种间基因交流频繁, 遗传分化 & \\
Boeta horse, Sharta horse, & & 程低。 & \\
Yuta horse & & \\
\hline
\end{tabular}

\section{参考文献}

Achmann R, Curik I, Dovc P, Kavar T, Bodo I, Habe F, Marti E, Solkner J, Brem G (2004) Microsatellite diversity, population subdivision and gene flow in the Lipizzan horse. Animal Genetics, 35, 285-292.

Binns MM, Boehler DA, Bailey E, Lear TL, Cardwell JM, Lambert DH (2012) Inbreeding in the Thoroughbred horse. Animal Genetics, 43, 340-342.

Chauhan M, Gupta AK, Dhillon S (2011) Genetic diversity and population structure of three Indian horse breeds. Molecular Biology Reports, 38, 3505-3511.

Chysyma R, Khrabrova L, ZAITSEV A, Makarova EY, Fedorov YN, Ludu B (2017) Genetic diversity in Tyva horses derived from polymorphism of blood systems and microsatellite DNA. Agricultural Biology, 52, 679-685.

Cozzi MC, Strillacci MG, Valiati P, Rogliano E, Bagnato A, Longeri M (2018) Genetic variability of Akhal-Teke horses bred in Italy. Peerj, 6, e4889.

Dorji J, Tamang S, Tshewang T, Dorji T, Dorji TY (2018) Genetic diversity and population structure of three traditional horse breeds of Bhutan based on 29 DNA microsatellite markers. PLoS ONE, 13, e0199376.

Du D, Deng L, Zhao C, Han G, Wu C (2009) Study on the genetic diversity of Ningqiang pony and Mongolian horse using microsatellite markers. Chinese Journal of Animal Science, 45, 10-13.

Grilz-Seger G, Druml T, Neuditschko M, Dobretsberger M, Horna M, Brem G (2019) High-resolution population structure and runs of homozygosity reveal the genetic architecture of complex traits in the Lipizzan horse. BMC Genomics, 20, 1-17.

Grilz-Seger G, Mesarič M, Cotman M, Neuditschko M, Druml T, Brem G (2018) Runs of homozygosity and population history of three horse breeds with small population size. Journal of Equine Veterinary Science, $71,27-34$.

Khanshour A, Conant E, Juras R, Cothran EG (2013) Microsatellite analysis of genetic diversity and population structure of Arabian horse populations. Journal of Heredity, 104, 386-398.

Kim NY, Seong HS, Kim DC, Park NG, Yang BC, Son JK, Shin SM, Woo JH, Shin MC, Yoo JH, Choi JW (2018) Genome-wide analyses of the Jeju, Thoroughbred, and Jeju crossbred horse populations using the high density SNP array. Genes \& Genomics, 40, 1249-1258.

Kusza S, Priskin K, Ivankovic A, Jedrzejewska B, Podgorski T, Javor A, Mihok S (2013) Genetic characterization and population bottleneck in the Hucul horse based on microsatellite and mitochondrial data. Biological Journal of the Linnean Society, 109, 54-65.

Ling YH, Ma YH, Guan WJ, Cheng YJ, Wang YP, Han JL, Mang L, Zhao QJ, He XH, Pu YB, Fu BL (2011) Evaluation of the genetic diversity and population structure of Chinese indigenous horse breeds using 27 microsatellite markers. Animal Genetics, 42, 56-65.

Luis C, Juras R, Oom M, Cothran E (2007) Genetic diversity and relationships of Portuguese and other horse breeds based on protein and microsatellite loci variation. Animal Genetics, 38, 20-27.

McCue ME, Bannasch DL, Petersen JL, Gurr J, Bailey E, Binns MM, Distl O, Guerin G, Hasegawa T, Hill EW, Leeb T, Lindgren G, Penedo MC, Roed KH, Ryder OA, Swinburne JE, Tozaki T, Valberg SJ, Vaudin M, 
陶克涛，韩海格，赵若阳，图格琴，芒来，白东义. 家马的驯化起源与遗传演化特征.生物多样性, 2020, 28 (6): 734-748. http://www.biodiversity-science.net/fileup/PDF/2020005

Lindblad-Toh K, Wade CM, Mickelson JR (2012) A high density SNP array for the domestic horse and extant Perissodactyla: utility for association mapping, genetic diversity, and phylogeny studies. PLoS Genetics, 8, e1002451.

Meira CT, Curi RA, Silva JAIIV, Correa MJM, de Oliveira HN, da Mota MDS (2013) Morphological and genomic differences between cutting and racing lines of Quarter horses. Journal of Equine Veterinary Science, 33, 244-249.

Petersen JL, Mickelson JR, Cothran EG, Andersson LS, Axelsson J, Bailey E, Bannasch D, Binns MM, Borges AS, Brama P, da Camara Machado A, Distl O, Felicetti M, Fox-Clipsham L, Graves KT, Guerin G, Haase B, Hasegawa T, Hemmann K, Hill EW, Leeb T, Lindgren G, Lohi H, Lopes MS, McGivney BA, Mikko S, Orr N, Penedo MC, Piercy RJ, Raekallio M, Rieder S, Roed KH, Silvestrelli M, Swinburne J, Tozaki T, Vaudin M, C MW, McCue ME (2013) Genetic diversity in the modern horse illustrated from genome-wide SNP data. PLoS ONE, 8, e54997.

Sadeghi R, Moradi-Shahrbabak M, Ashtiani SRM, Schlamp F, Cosgrove EJ, Antczak DF (2019) Genetic diversity of Persian Arabian horses and their relationship to other native Iranian horse breeds. Journal of Heredity, $110,173-182$.

Tozaki T, Kikuchi M, Kakoi H, Hirota K, Nagata S, Yamashita D, Ohnuma T, Takasu M, Kobayashi I, Hobo S, Manglai D, Petersen JL (2019) Genetic diversity and relationships among native Japanese horse breeds, the Japanese Thoroughbred and horses outside of Japan using genome-wide SNP data. Animal Genetics, 50, 449-459.

Tozaki T, Takezaki N, Hasegawa T, Ishida N, Kurosawa M, Tomita M, Saitou N, Mukoyama H (2003) Microsatellite variation in Japanese and Asian horses and their phylogenetic relationship using a European horse outgroup. Journal of Heredity, 94, 374-380.

Zeng LL, Chen NB, Yao YB, Dang RH, Chen H, Lei CZ (2019) Analysis of genetic diversity and structure of Guanzhong horse using microsatellite markers. Animal Biotechnology, 30, 95-98. 